\title{
Conscious and Unconscious Sensory Inflows Allow Effective Control of the Functions of the Human Brain and Heart at the Initial Ageing Stage
}

\author{
Anatolij T. Bykov ${ }^{1}$, Tatyana N. Malyarenko', Yurij E. Malyarenko ${ }^{1}$, \\ Vladimir P. Terentjev ${ }^{2}$ and Alexandr A. Dyuzhikov ${ }^{2}$ \\ ${ }^{1}$ F. E. Dzerzhinskij Central Clinical Sanatorium, Sochi, Russia \\ ${ }^{2}$ Rostov Centre of Cardiology, Rostov-on-Don, Russia
}

\begin{abstract}
The authors of the present article based their assumption on the concept that the sensory systems are the "windows to the brain" through which various functions of the human organism can be controlled. Comprehension of the fundamental mechanisms of the optimization of the sensory systems, brain, and cardiac functions has increased based on the prolonged sensory flows using conscious and unconscious aromatherapy and multimodal sensory activation. Sensory flow evoked stable systemic responses, including adaptive alteration of psycho-emotional state, attention, memory, sensorimotor reactions, intersensory interaction, visual information processing, statokinetic stability, and autonomic heart rhythm control. The efficacy and expediency of the use of sensory flow for nonmedicinal correction of vital functions of the human organism at the initial stages of ageing was revealed.

Keywords: correction of functions, sensory flows, integrative brain activity, conscious and unconscious, ageing, aromatherapy
\end{abstract}

\begin{abstract}
Los autores de este artículo se basan en el concepto de que los sistemas sensoriales son las "ventanas al cerebro" a través de las cuales se pueden controlar varias funciones del organismo humano. La comprensión de los mecanismos fundamentales de la optimización del sistema sensorial, del cerebro, y de las funciones cardíacas ha aumentado gracias a los flujos sensoriales prolongados empleando la aromaterapia consciente y no consciente y la activación sensorial multimodal. El flujo sensorial evocó respuestas sistémicas estables, incluyendo la alteración adaptativa del estado psico-emocional, la atención, la memoria, reacciones sensorimotores, la interacción intersensorial, el procesamiento de la información visual, la estabilidad estatoquinestésica y el control del ritmo cardíaco autonómico. Se observa la eficacia y la conveniencia del empleo del flujo sensorial para la corrección no farmacológica de las funciones vitales del organismo humano en los estadios iniciales del envejecimiento.

Palabras clave: corrección de funciones, flujos sensoriales, actividad cerebral integrativa, percibido y no percibido, envejecimiento, aromaterapia.
\end{abstract}

Correspondence concerning this article may be addressed to Professor Yurij E. Malyarenko, F.E. Dzerzhinskij Central Clinical Sanatorium, 35 Vinogradnaya Street, Sochi, 354010, Russia. E-mail: san@ sochi.ru 
As well known, senile changes in the central nervous system (CNS) occur relatively early and can be detected at the age of 30 (Khavinson, Kvetnoy, Ingel, \& Marianovich, 2003). These changes include the disconnection of the brain regulation systems and the reduction of hypothalamic control (Appenzeller, 1992). Ageing affects all components of the autonomic nervous system leading to the attenuation of adequate reactions to various conditions of internal and external environment. With increasing age, there are irreversible changes in sensory systems, a decrease of intersensory integration (Manchester, Voollacott, ZederbauerHylton, \& Marino, 1989), and the development of orthostatic instability (Bannister \& Mathias, 1992). Furthermore, there is a decrease in energetic brain potential (Fokin \& Ponomareva, 2003) and deterioration of cognitive function (Baltes \& Lindenberger, 1997). The significance of the disturbance of interrelations of cognitive and sensory function in ageing has been pointed out (Bashore, Ridderinkhof, \& van der Molen, 1997).

It has been demonstrated that, in borderline states, the use of non-medicinal treatment, and in particular, aromatherapy is notably effective (Bykov, \& Malyarenko, 2003a, 2003b). Some authors (Malyarenko, Bykov, Malyarenko, Matyukhov, \& Korabelnikova, 2005) are of the opinion that physiological ageing should be considered one of the borderline states (according to Galen and Avicenna - neither a state of health nor of disease, but a third functional state between normalcy and pathology) in which self-regulatory functions and adaptive resources decline.

The optimization of human functions using sensory (information) flow has a long and substantial history. Nevertheless, the methodological basis of such technology and the argumentation for its practical use require a contemporary scientific standing (Buckle, 2004; Cooke \& Ernst, 2000; King, 1994). In relation to the technology of sensory flow, some authors think that aromatherapy is the most beneficial (Buckle; Price, \& Price, 2004), whereas others are in favor of a comprehensive flow generated by the alpha-capsule, for example (Malyarenko, Bykov, \& Malyarenko, 2005; Roebuck, 1995).

The importance of the use of aromas for the correction of the organism's functional state has changed over time. At one point, this method was practically forgotten and, subsequently, it suddenly became the center of attention, and aromatherapy was given a new development impulse. Over the past few years, this development was determined by breakthroughs in fundamental science related to the structural and functional organization of the olfactory system and a novel understanding of the mechanisms of scent perception (Dawes, Dawes, \& Williams, 2004; Doty, 2001; Galan, Sachse, Galizia, \& Herz, 2004; Herz, Beland, \& Hellerstein, 2004; Herz, Schankler, \& Beland, 2004; Royet, Koenig, Gregoire, Cinotti, \& Lavene, 2000). Buck and Axel were awarded the Nobel Prize in 2004 (Malcolm, 2004) for the series of studies that led to the revelation of the molecular basis of scent recognition, and significantly extended the scope of comprehension of the functional capabilities of the olfactory system. It has also been revealed that the olfactory bulb is one of the principal structures of neoneurogenesis of the mature human brain (Loseva \& Karnup, 2004) and is an outpost of sorts, protecting the brain from pathogenic factors. In old age, neoneurogenesis slows down, resulting in an increase of the probability of damage to the CNS cells with consecutive memory impairment. Interest in the olfactory system has also been aroused by the fact that a loss of the ability to perceive scents is one of the first signals of the development of a neurodegenerative disease, including Alzheimer's and Parkinson's diseases or, at least, of cognitive dysfunction in the elderly (Graves, Bowen, Rajaram, McCormick, \& McCurry, 1999; Hawkes, Shepard, \& Daniel, 1997).

In relation to the comprehensive sensory flow, the multisystem impairment in borderline states between health and disease - among which age-related involution of physiologic systems should be considered-determines the need for the comprehensive use of physical factors to correct the multilevel activation of the CNS, leading to the enhancement of the integration process (Bykov \& Malyarenko, 2003b; Malyarenko, Bykov, \& Malyarenko, 2005; Malyarenko, Bykov, Malyarenko, Matyukhov, et al., 2005).

Due to this and to other researches, sensory flow technology is now widespread in clinical practice (Buckle, 2004; Price \& Price, 2002). However, many of the mechanisms and effects of sensory activation remain unknown, especially in ageing. First of all, this is in relation to the role of unconscious sensory flows and the formation of a systemic response, the components of which may be changes in statokinetic stability, equilibrium of autonomic regulation of cardiac rhythm (CR), inter-sensory interrelations, the perception and processing of information, and other mental processes. Therefore, the present article was written as a response to the pragmatic demand for further study of the efficacy of conscious and unconscious aromatherapy, as well as of the comprehensive sensory flow in the optimization of cardiac and brain functions at the initial stages of ageing.

The working hypothesis of this study was based on the following facts:

1. Sensory systems are the "windows to the brain" through which one can regulate various functions (Baltes \& Lindenberger, 1997; Bykov \& Malyarenko 2003a, 2003b).

2. The olfactory sensory system, as one of the oldest systems, has played a leading role in the formation of adaptive reactions and part of the key structures of the brain (the limbic system), of which the integration with other brain structures is provided by over 30 tracts.

3. Sensory flow is largely responsible for the brain's energetic potential (Fokin \& Ponomareva, 2003). 
Sensory flow deprivation leads to depletion of brain energy, it slows down integration processes, resulting in accelerated ageing (Stuart-Hamilton, 2000). Sensory deprivation usually occurring in old age is the prerequisite for the dysregulation of sensory systems, the CNS, and autonomic functions (Gordeeva, 2004a, 2004b).

4. During ageing there is an increase in the dependence of functional systems and conditional afferentation (Sudakov, 1987). Thus, the implementation of prolonged sensory flow aimed at function correction in ageing offers significant promise (Bykov \& Malyarenko, 2003b).

\section{Method}

\section{Participants}

Sixty-five women, aged between 50-55 years, participated in the study (all participants were in the second phase of menopause), with high or low levels of anxiety and clinically diagnosed neurocirculatory dystonia of sympathetic or parasympathetic type. Three study series were carried out with unconscious $(n=19)$ and conscious $(n=20)$ aromatherapy, and comprehensive sensory flow $(n=20)$ generated by the alpha-capsule. Two control groups consisted of 6 women of comparable age and functional state who spent 30 minutes per day for 8 days seated in comfortable seats and conditions without aromatherapy, or lying in the alphacapsule without comprehensive sensory flow. Positive conditioning to the results of treatment was not carried out in any of the series. Participants receiving unconscious aromatherapy were unaware of the treatment.

\section{Procedures}

The choice of type and regimen of intervention was based on the following principles: (a) psychological comfort, (b) comprehensive effect, (c) prolonged intervention allowing for the attainment of stable adaptation mechanisms, (d) minimal invasiveness, and (e) individualism.

Sensory system activation. For the administration of olfactory sensory flow, aromas created by combining four phytogenic essences (30-min daily sessions for 8 days) were used: Lavandula angustifolia, Citrus limon, Mentha piperita, Abies sibrica. These plant aromas were used because the essence components of Abies sibrica are regulators of the ANS; Mentha piperita essence activates visual perception; the active components of Lavandula angustifolia reduce the influence of exogenous emotions by increasing the concentration of GABA in the inhibitory neurons of the amygdala (Le Doux, 1996); Citrus limon and Lavandula angustifolia essences have a sedative effect (Franchomme \& Pènoël, 1990; Roulier, 1990). The use of blends of essences were supposed to increase the comprehensiveness of treatment first and foremost on the limbic system with its multifaceted functions.

During sessions of aromatherapy, participants were seated in comfortable seats on the premises with lowered lighting and sound isolation. Effect strength in one of the series was unconscious (at $20 \%$ below the individual threshold). In the other series, the strength was twice the threshold level, that is, conscious. Individual perception thresholds of the essence blends were determined the day before commencement of the study.

Multimodal influence. In the present study, comprehensive sensory flow of the alpha-capsule (8-10 sessions in the various groups) included music, the aroma of a blend of lemon, lavender, and mint essence, and a vibration massage. Within the capsule, an atmosphere of a dry sauna, with air temperature of $43^{\circ} \mathrm{C}$, was maintained. Most of the aforementioned sensory flows are, in effect, comprehensive. Music activates not only auditory receptors, but also skin vibration receptors; essence molecules activate olfactory receptors and, through the blood, chemoreceptors of various physiological systems; vibration massage stimulates extra- and interoreceptors as well as the afferents of peripheral blood vessels accompanied by the production of heat and cutaneous tissue hormones. It is important that, within the capsule, a dry sauna atmosphere is maintained, as evaporation energy is spent on cooling the air in the lungs and near the skin and, therefore, direct heating of the body is significantly limited. The alpha-capsule is installed on the premises and isolated from external influence. One can assume that the use of the alpha-capsule, with its activation of several sensory systems, provides optimal conditions for the activation of the integrative activity of the brain and the formation of a systemic response.

\section{Measurements and Data Analyses}

Investigation reaction responses. We assessed changes of anxiety level, attention, psycho-emotional resistance to interference, long-term memory, latent period, and accuracy of sensorimotor reactions (SMR), statokinetic stability, visual information processing productivity, and changes in autonomic CR regulation and autonomic activity regulation. Our assumptions were based foremost on the fact that SMR are an important characteristic of brain activity. Stabilography is a sensitive and informative indicator of the functional state of the organism (Allum \& Shepard, 1999). As of the publications of Malliani (1996), analysis of the cardiac rhythm variability (CRV) is considered a modern view. CRV reflects the functional state of the entire organism; furthermore, it is considered that excessive periodicity or chaos, as well as rigidity, is evidence of deterioration of regulatory processes, including those related to cardiac rhythm. 
Anxiety level was determined using the Lüscher 8-color subtest method. Assessment of attention and long-term visual memory was carried with the corresponding computer programs (standard red-and-black Schulte-Platonov and geometric figure tables). The assessment of the visual information processing effectiveness was conducted using Waston-Tagaeva proof correction tests. The visual productiveness coefficient was calculated with the formula:

$$
V=n / N \cdot n / t
$$

where $V$ is the visual productiveness coefficient; $n$ is the number of correctly noted symbols of required configuration; $N$ is the total number of symbols of required configuration in the table; and $t$ is the time spent on the performance of the test. Time and accuracy of simple and complex visiomotor reactions (SVMR and CVMR, respectively) were determined using the psychophysiological complex PFK2001 (Russia). During the entire testing time, graphs for each of the 30 reactions were automatically calculated, allowing for the graphic demonstration of individual reaction variability, as well as the mean reaction time and number of errors in the differentiation of stimuli in the CVMR. The difference between CVMR- and SVMR-time served as the basis for the assessment of the mental component of CVMR: the time required for the perception of the stimulus and decision making.

Involuntary and voluntary regulation of vertical stance was assessed using a computer stabilograph with visual feedback "Stabilan-01" (Russia) and a special dynamometric platform registering oscillations of the overall pressure center. The quality of involuntary regulation of the vertical stance was determined by the results of the Romberg test with open and closed eyes in conditions of distracted attention. The magnitude of ellipse area of the stabilogram $(\mathrm{mm})$ and integrative indexes of quality of balance (in percentages) were evaluated. Voluntary regulation of vertical stance was assessed by the reserve of overall pressure center shift on the support area $(\mathrm{mm})$ without the loss of balance in the vertical axis body deflection backwards-forwards and sideto-side. Investigation was carried out in a partially darkened and sound-proofed room.

Registration and analysis of CRV were carried out using the equipment and software complex for the registration and processing of electrocardiograms of CARD type (Russia). Automatic analysis of CRV was carried out in accordance with the recommendations of the Task Force of the European Society of Cardiology and North American Society of Pacing and Electrophysiology (1996), allowing for the assessment of the extent of neurohumoral/central and autonomic regulation of $\mathrm{CR}$, as well as the balance between the activity of sympathetic and parasympathetic cardiac regulation. According to changes in CRV during the active orthostatic test carried out by standard method, the autonomic maintenance of activity was evaluated.

The determination of the above-mentioned functions was carried out before commencing treatment, on the day after completion of all sessions of sensory stimulation, and the stability of the acquired result of some of the functions was rated 2 weeks after treatment.

Statistical indexes (means, root-mean-square deviation, and indexes of significance of variance at various stages of the study) were automatically calculated using the software package Statistica-5.

\section{Results}

\section{Aromatherapy}

We observed that both conscious and unconscious aromatherapy caused a normalization of anxiety level in all

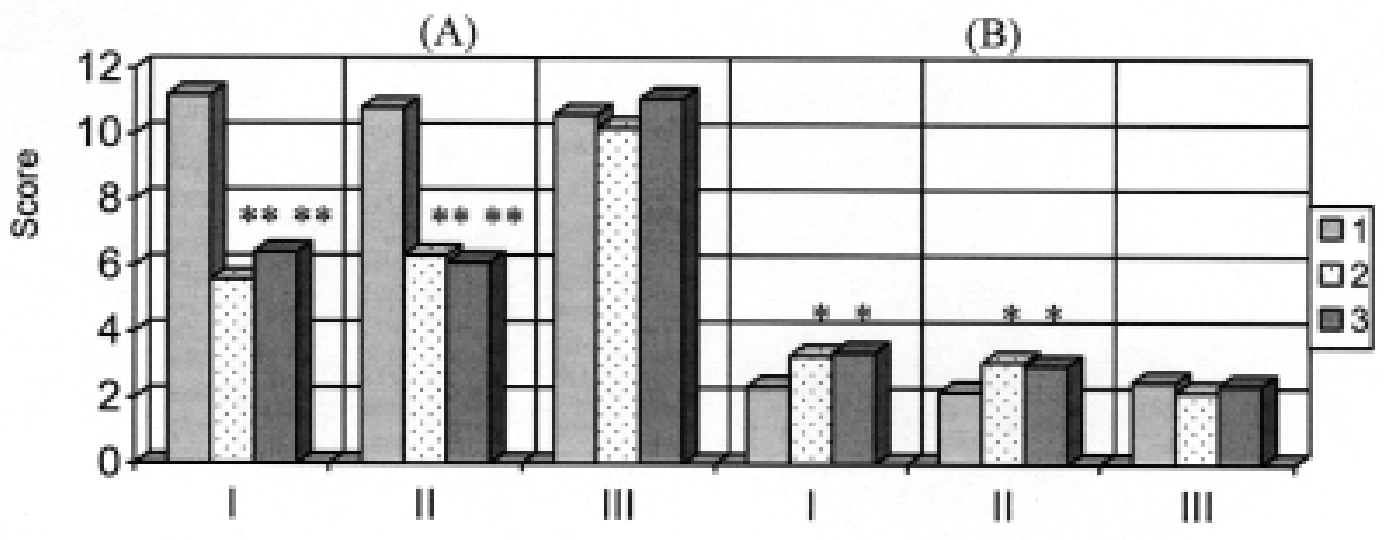

Figure 1. Alterations in anxiety level in women aged 50-55 years with high (A) and low (B) initial anxiety levels in groups under the influence of perceived (I) and unperceived (II) aromatherapy and in the control group without influence (III). 1= initial level; $2=$ after eight sessions; $3=2$ weeks after the eight sessions and at the same timeframes in the control group. $* p \leq .05 . * * p=.001$ (significance of variance in relation to initial values). 


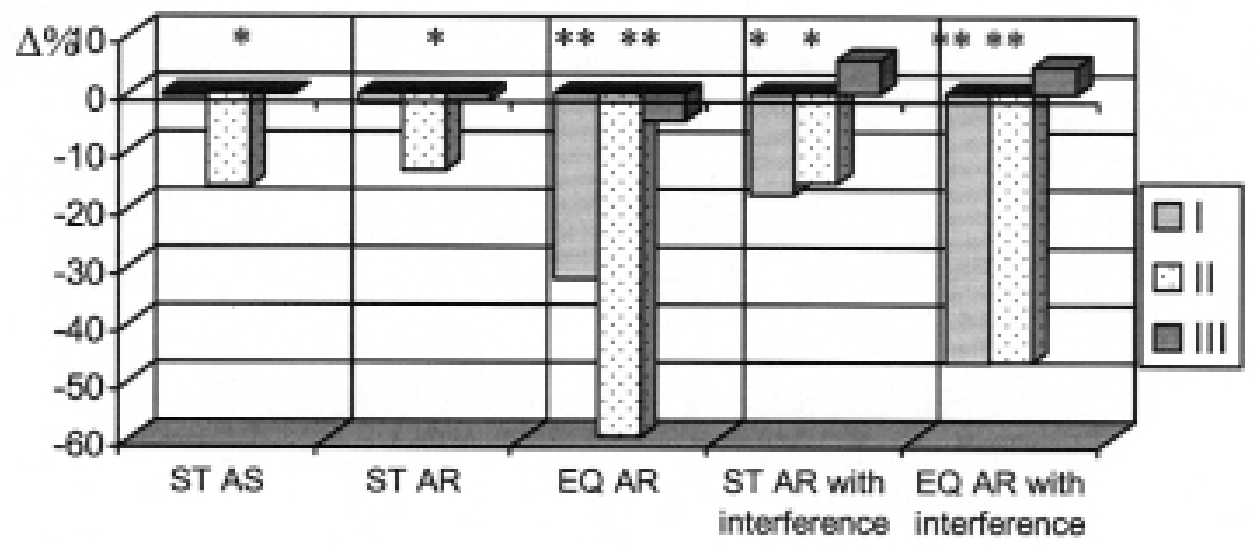

Figure 2. Alteration in mean indices of attention in women aged 50-55 years under the influence of eight sessions of perceived (I) and unperceived (II) prolonged aromatherapy and in the control group without influence (III) in percentage in relation to initial values. Notations: ST = mean target stimulus search time in ms; AS = attention selectivity; AR = attention redirection; EQ = error quantity. $* p \leq .05 . * * p=.001$.

participants (Figure 1): With initially high levels of anxiety, after eight sessions, there was a decrease of the indexes practically to the upper limits of normative values (mean decrease $50.2 \%$ with conscious olfactory flow and $32.2 \%$ with unconscious flow). In participants with very low initial levels of anxiety, there was an increase in index level to the lower limits of normative values (mean values $40.7 \%$ and $36.3 \%$ decrease, respectively). The attained changes were maintained 2 weeks after the sessions.

Investigation of the influence of aromatherapy on attention showed that selectivity and convertibility of attention significantly improved as a result of unconscious olfactory flow (Figure 2). On average, in both versions of aromatherapy, participants' resistance to interference changed equally in stimulus pursuit time and differentiation accuracy.
An increase in the effectiveness of CNS activity in the performance of SMR was noted. As displayed in Figure 3, the most noticeable change was observed in relation to SMR accuracy. The significant reduction in the amount of differentiation errors reflects the improvement of these processes and an increase in concentration. The reduction of SVMR- and CVMR-time, as well as the CVMR mental component, was relatively less pronounced with unconscious aromatherapy in comparison with conscious aromatherapy, and the increase in reaction accuracy compared to initial values was significantly greater in conscious aromatherapy. Positive changes in SMR performance were not only maintained after treatment completion, but also continued to increase. For example: after eight aromatherapy sessions, SVMR-time was lower at 2 weeks than 5 days after the
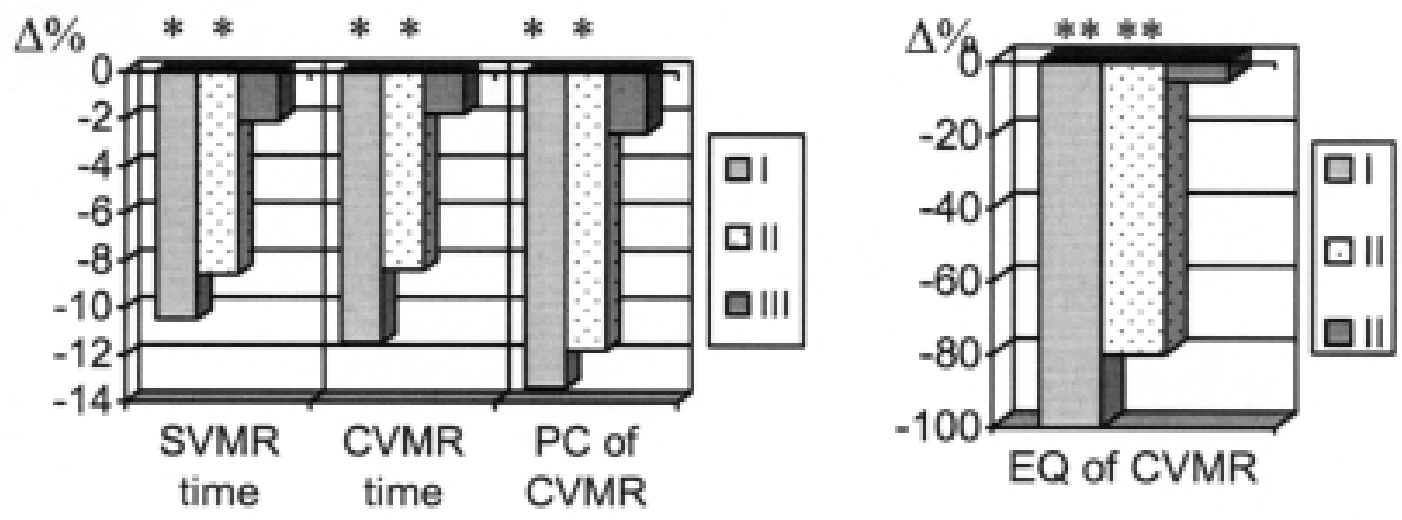

Figure 3. Improvement of mean group indices of visual-motor reactions of women aged 50-55 years under the influence of eight sessions of prolonged perceived (I) and unperceived (II) aromatherapy and eight days without treatment in the control group (III).

Notations: SVMR = simple visual-motor reaction; $\mathrm{CVMR}=$ complex visual-motor reaction $($ dual choice $)$; $\mathrm{PC}=$ psychological component of CVMR; EQ = error quantity of differentiation of stimuli in CVMR.

$* p \leq .05$. ** $p=.001$. 


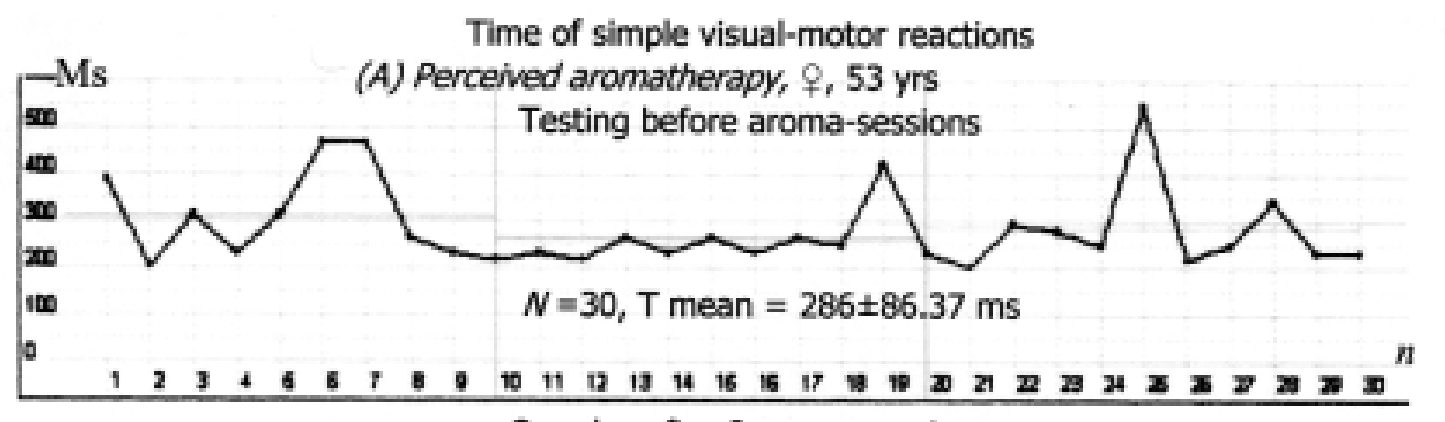

One day after 8 aroma-sessions
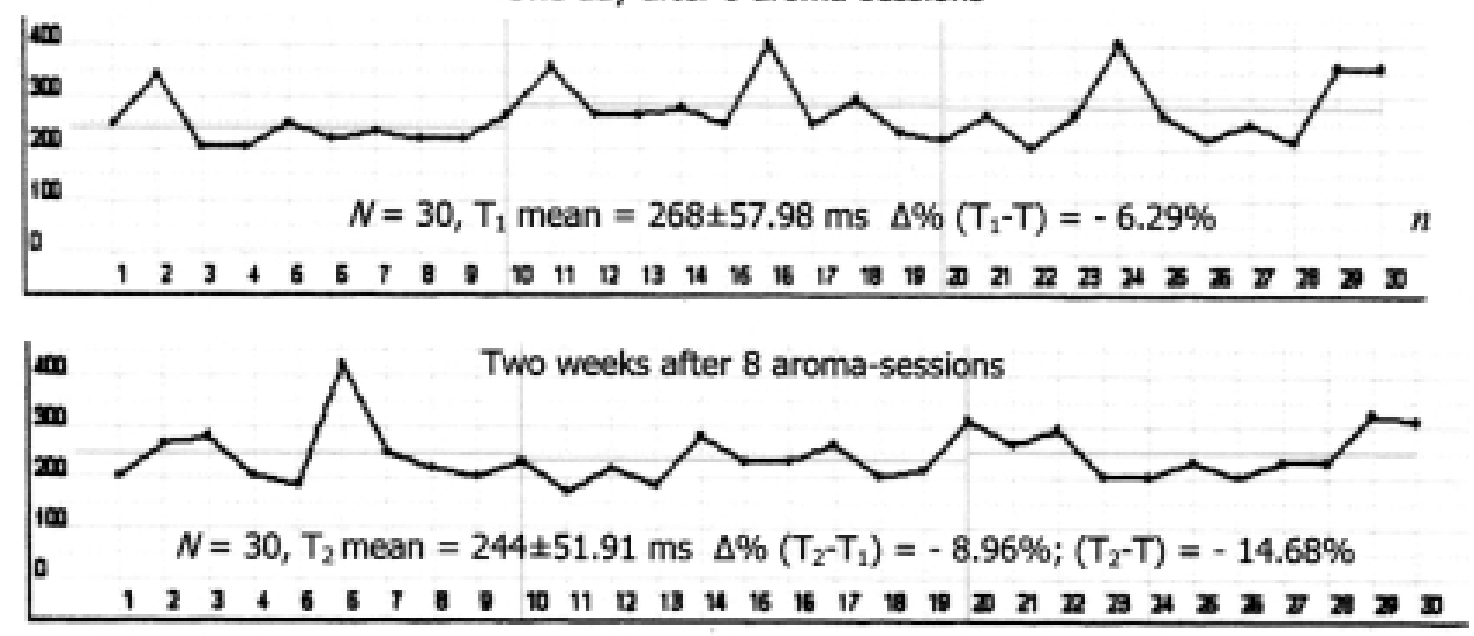

(B) Unperceived aromatherapy, o, 55 yrs
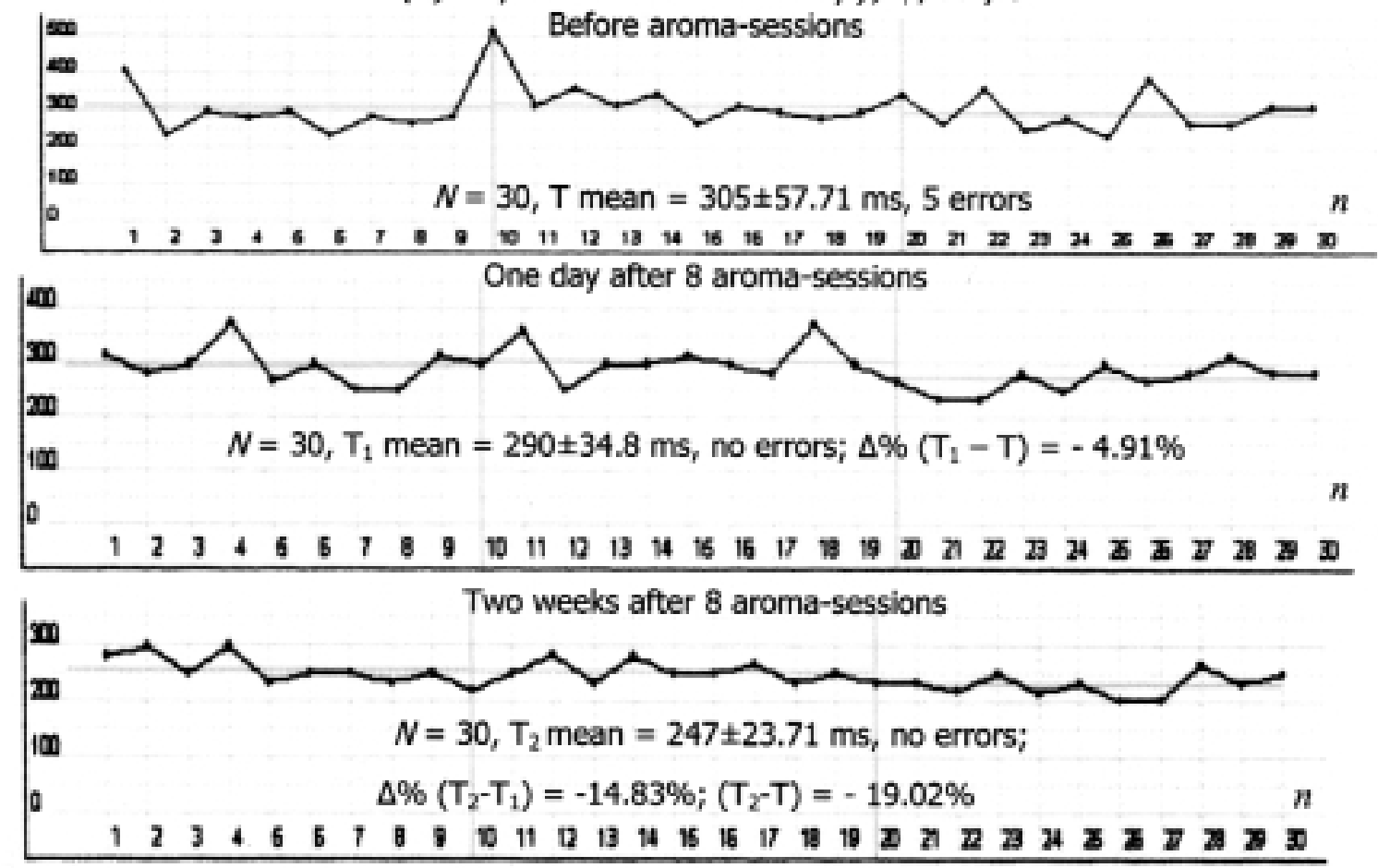

Figure 4. Alterations in the individual time of simple visual-motor reactions and its variability in time with 30 attempts at each test in women aged 53 and 55 years under the influence of perceived (A) and unperceived (B) aromatherapy.

Notations: $\mathrm{n}=$ order number of reactions in each test with 30 attempts; $\mathrm{N}=$ number of attempts; $\mathrm{T}$ mean $=$ mean reaction time in each test $\left(\mathrm{T}=\right.$ before treatment; $\mathrm{T}_{1}=$ one day after eight sessions; $\mathrm{T}_{2}=$ two weeks after eight sessions). (Print-outs of test protocols). 
sessions, and more significantly so with unconscious treatment, and the decrease in reaction-time variability during test performance was also more noticeable in the case of unconscious olfactory activation (Figure 4). Note that in the control group, indexes of anxiety, SMR and attention remained practically unchanged (Figures 1, 2, 3).

Investigation of the indexes of participants' balance at initial stages of ageing showed that, under the influence of olfactory stimulation, there was an improvement of both involuntary and voluntary regulation of the vertical stance. However, there is a difference in the effects of conscious and unconscious sensory flow. As shown in Table 1, as a result of conscious olfactory stimulation, on average in the group, stabilogram area with involuntary regulation decreased significantly, in especially with open eyes. The integral balance quality index increased less, and with closed eyes, there was practically no change. As a result of unconscious aromatherapy, the stabilogram area with open eyes also decreased, though to a lesser magnitude. However, the integral balance quality with open eyes increased nine-fold in comparison with the indexes following the sessions of conscious aromatherapy. This may be evidence of the fact that, as a result of prolonged activation of the olfactory sensory system, the input of the visual system in mechanisms of involuntary posture regulation increases; the integral balance quality index was more greatly affected by unconscious aromatherapy. In the control group, all changes in indexes of involuntary vertical stance control were insignificant.

In relation to changes in the indexes of voluntary regulation of vertical stance after 8 sessions of both conscious and unconscious aromatherapy, there was an increase in the area of statokinetic stability in vertical axis body deflection, whereas changes in the control group were insignificant (Table 2). In deflection of the body backwards and forwards, the area of permissible overall pressure center deflection (without disruption of balance) on average increased more noticeably with unconscious aromatherapy. With deflection to the right, it increased more noticeably in conscious than in unconscious sensory flow, although there were more extensive individual variabilities, as shown in Figure 5. In deflections to the left, on average, unconscious aromatherapy (Table 2) did not cause significant changes in statokinetic stability, which may be due to the fact that, in most participants, this index was initially close to optimal. On the whole, the most positive changes in statokinetic stability were noted in deflections to the right (note that initial values in both groups were the worst). As a consequence of prolonged olfactory stimulation, as in the previous test, there was significant leveling out on inter-individual variance of

Table 1

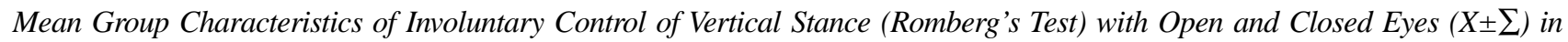
Women Aged 50-55 Years Before and After Eight Sessions of Prolonged Conscious and Unconscious Aromatherapy and in Controls

CONSCIOUS AROMATHERAPY ( 8 sessions, $n=20$ )

\begin{tabular}{cccccccc}
\hline \multicolumn{2}{c}{ Stabilogram ellipse area in $\mathrm{mm}^{2}$} & \multicolumn{3}{c}{ Balance function quality in $\%$} \\
Cpen eyes & \multicolumn{2}{c}{ Closed eyes } & \multicolumn{2}{c}{ Open eyes } & \multicolumn{2}{c}{ Closed eyes } \\
\hline $\begin{array}{c}\text { Before } \\
\text { sessions }\end{array}$ & $\begin{array}{c}\text { After } \\
\text { sessions }\end{array}$ & $\begin{array}{c}\text { Before } \\
\text { sessions }\end{array}$ & $\begin{array}{c}\text { After } \\
\text { sessions }\end{array}$ & $\begin{array}{c}\text { Before } \\
\text { sessions }\end{array}$ & $\begin{array}{c}\text { After } \\
\text { sessions }\end{array}$ & $\begin{array}{c}\text { Before } \\
\text { sessions }\end{array}$ & $\begin{array}{c}\text { After } \\
\text { sessions }\end{array}$ \\
\hline $89.2 \pm 18.55$ & $52.43 \pm 11.0$ & $90.1 \pm 27.4$ & $61.6 \pm 19.7$ & $85.0 \pm 16.5$ & $92.33 \pm 9.5$ & $89.34 \pm 16.8$ & $86.0 \pm 14.2$ \\
$\Delta \%$ & $-41.22 \% *$ & & $-31.63 \% *$ & $\Delta \%$ & $+8.62 \% *$ & $\Delta \%$ & $-3.73 \%$ \\
\hline
\end{tabular}

UNCONSCIOUS AROMATHERAPY ( 8 sessions, $n=19)$

\begin{tabular}{|c|c|c|c|c|c|c|c|}
\hline \multicolumn{4}{|c|}{ Stabilogram ellipse area in $\mathrm{mm}^{2}$} & \multicolumn{4}{|c|}{ Balance function quality in $\%$} \\
\hline \multicolumn{2}{|c|}{ Open eyes } & \multicolumn{2}{|c|}{ Closed eyes } & \multicolumn{2}{|c|}{ Open eyes } & \multicolumn{2}{|c|}{ Closed eyes } \\
\hline $79.8 \pm 19.9$ & $64.4 \pm 13.5$ & $93.5 \pm 23.7$ & $90.7 \pm 19.6$ & $64.5 \pm 17.0$ & $113.4 \pm 24.6$ & $83.75 \pm 15.3$ & $87.0 \pm 17.1$ \\
\hline$\Delta \%$ & $-19.29 \% *$ & & $-4.91 \%$ & $\Delta \%$ & $+75.8 \% * *$ & $\Delta \%$ & $+3.88 \%$ \\
\hline
\end{tabular}

CONTROL GROUP $(n=6)$

\begin{tabular}{cccccccc}
\hline \multicolumn{3}{c}{ Stabilogram ellipse area in $\mathrm{mm}^{2}$} & \multicolumn{4}{c}{ Balance function quality in $\%$} \\
\multicolumn{2}{c}{ Open eyes } & \multicolumn{2}{c}{ Closed eyes } & \multicolumn{2}{c}{ Open eyes } & \multicolumn{2}{c}{ Closed eyes } \\
Initial & In 8 days & Initial & In 8 days & Initial & In 8 days & Initial & In 8 days \\
\hline $78.8 \pm 31.6$ & $76.4 \pm 31.2$ & $91.8 \pm 32.6$ & $92.7 \pm 34.5$ & $76.6 \pm 26.7$ & $73.5 \pm 23.4$ & $85.2 \pm 21.7$ & $86.4 \pm 22.3$ \\
$\Delta \%$ & $-3.05 \%$ & & $+0.98 \%$ & $\Delta \%$ & $+4.05 \%$ & $\Delta \%$ & $+1.41 \%$ \\
\hline
\end{tabular}

$* p \leq .05 . * * p=.001$. 
Table 2

Alterations in Stability Zone with Vertical Axis Deflection in Women Aged 50-55 Years under the Influence of Eight Sessions of Conscious and Unconscious Prolonged Aromatherapy and in Controls

\begin{tabular}{|c|c|c|c|c|c|c|}
\hline \multirow[b]{3}{*}{ Direction of deflection } & \multicolumn{4}{|c|}{ Permissible deflection of OPC without loss of balance $(\mathrm{M} \pm \sigma$ in $\mathrm{mm})$} & & \\
\hline & \multicolumn{2}{|c|}{$\begin{array}{l}\text { Conscious aromatherapy } \\
\qquad(n=20)\end{array}$} & \multicolumn{2}{|c|}{$\begin{array}{l}\text { Unconscious aromatherapy } \\
\qquad(n=19)\end{array}$} & \multicolumn{2}{|c|}{$\begin{array}{c}\text { Controls } \\
(n=6)\end{array}$} \\
\hline & $\begin{array}{c}\text { Before } \\
\text { sessions }\end{array}$ & $\begin{array}{c}\text { After } \\
\text { sessions }\end{array}$ & $\begin{array}{c}\text { Before } \\
\text { sessions }\end{array}$ & $\begin{array}{c}\text { After } \\
\text { sessions }\end{array}$ & Initial & In 8 days \\
\hline \multirow{2}{*}{ Forward } & $94.33 \pm 33.5$ & $107.67 \pm 31.5$ & $83.0 \pm 28.3$ & $115.5 \pm 16.3$ & $79.9 \pm 29.6$ & $81.6 \pm 23.7$ \\
\hline & $\Delta \%$ & $+14.14 \% *$ & $\Delta \%$ & $+39.16 \% * *$ & $\Delta \%$ & $+2.13 \%$ \\
\hline \multirow{2}{*}{ Backward } & $69.33 \pm 18.03$ & $76.0 \pm 19.1$ & $70.25 \pm 23.7$ & $83.75 \pm 15.8$ & $64.4 \pm 28.3$ & $65.9 \pm 27.1$ \\
\hline & $\Delta \%$ & $+9.62 \% *$ & $\Delta \%$ & $+19.22 \% *$ & $\Delta \%$ & $+2.31 \%$ \\
\hline \multirow{2}{*}{ To the right } & $46.0 \pm 19.1$ & $107.7 \pm 20.5$ & $66.75 \pm 28.4$ & $127.5 \pm 18.5$ & $52.7 \pm 19.6$ & $54.4 \pm 14.8$ \\
\hline & $\Delta \%$ & $+134.13 \% * *$ & $\Delta \%$ & $+91.01 \% * *$ & $\Delta \%$ & $+3.83 \%$ \\
\hline \multirow{2}{*}{ To the left } & $80.33 \pm 31.43$ & $90.0 \pm 26.2$ & $124.5 \pm 27.0$ & $121.0 \pm 17.03$ & $92.3 \pm 33.7$ & $90.4 \pm 31.1$ \\
\hline & $\Delta \%$ & $+12.03 \% *$ & $\Delta \%$ & $-0.03 \%$ & $\Delta \%$ & $+2.06 \%$ \\
\hline
\end{tabular}

Note. OPC $=$ overall pressure center of the body on the support.

$* p \leq .05 .{ }^{* *} p=.001$

statokinetic stability indexes. Positive changes in balance reserves in body deflection were best maintained after unconscious aromatherapy (Figure 5).

Investigation of $\mathrm{CR}$ regulation showed that, in women of age 50-55 years with a predominance of the sympathetic nervous system direction of CRV changes, the influence of both conscious and unconscious olfactory sensory flow was of a homeostatic nature (Figure 6). On average, in both types of treatment, there was a significant increase in respiratory arrhythmia, total power of regulatory influence on CR with poor initial expression prior to treatment, and a decrease in sympathetic and parasympathetic activity (low frequency/high frequency or $\mathrm{LF} / \mathrm{HF}$ ) to the state of autonomic equilibrium. On average, in the group receiving conscious stimulation, the LF/HF index was initially 3.2 units and after treatment the index dropped to 1.1 units. In unconscious aromatherapy, the LF/HF index dropped to an average level of 0.95 units. With an initial predominance of supra-segmental ergotropic structure influence on CR in women with excitable anxiety, the study revealed a decrease in centralized cardiac activity regulation according to the VLF index. The described changes of CRV with unconscious aromatherapy are graphically displayed (Figure 7A and 7C).

The optimizing effect of conscious and unconscious olfactory sensory flow was noted in the analysis of its effect on the autonomic regulation of postural reactions. In cases of inadequately intense sympathetic or central (neurohumoral and metabolic) reactions, the influence of olfactory stimulation in response to active orthostatic testing resulted in more economic $\mathrm{CR}$ regulation with a replacement of parasympathetic insufficiency with its normal activity. In cases of initial insufficient sympathetic nervous system mobilization in postural change (Figure 7B), there was an increase of its activity to adequate levels and an improvement of the overall power of regulatory influence on CR in a vertical position (Figure 7D).

On the whole, in treatment with unconscious essences, changes in CRV were on average 2-8\% less than in the series with conscious scents. All the changes displayed in Figures 6 and 7 can be interpreted as positive, conducive to the optimization of CR regulation in states of calm wakefulness, and to the improvement of autonomic regulation of vertical stance in women at early stages of ageing, even with the use of unconscious aromatherapy. In the control group, CRV indexes remained practically unchanged over the 8-day period.

\section{Multimodal Sensory Flow}

According to literature, sessions of comprehensive sensory flow of the alpha-capsule result in detoxication of the body and prevents neurodegenerative diseases, as well as the improvement of metabolism, and it corrects body mass, increases the energetic potential and slows down ageing (Alpha 2010 ${ }^{\mathrm{TM}}$ Spa System, 2002). The present study assessed other effects not researched previously.

Multimodal activation of sensory systems in the alphacapsule resulted in a significant decrease in anxiety (on average from 9.8 to 4.5 points on the Lüscher test) and improvement of mechanisms of retrieval and processing of 
(A) Perceived Aramathoragy 9, 55 yrs

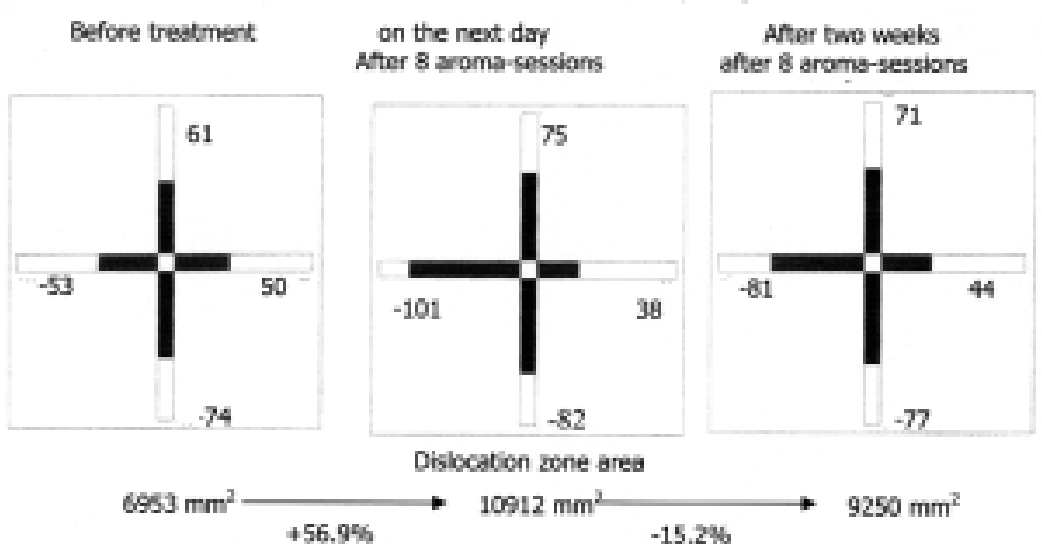

(B) Unperceived aromatherapy 9,54 yrs

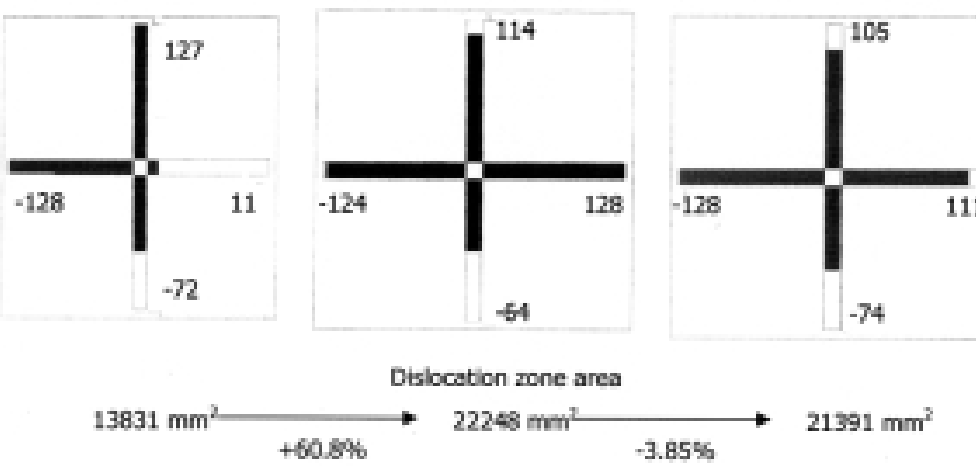

Figure 5. Alteration in the individual stability zone in body deflection forward-right-backward-left in two women aged 54 and 55 years under the influence of perceived (A) and unperceived (B) prolonged aromatherapy (figures indicate deflection of overall pressure center in mm without loss of balance).

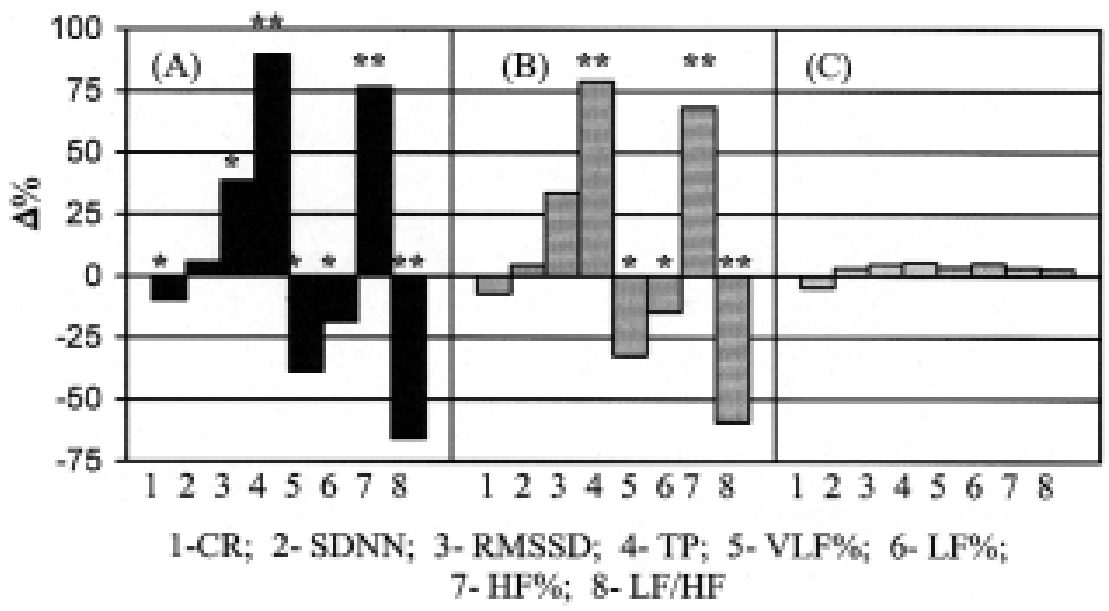

Figure 6. Alterations in mean group indices of cardiac rhythm variability in percentage in relation to initial values under the influence of an 8-day course of aroma sessions in women aged 50-55 years with initial disturbance of cardiac rate regulation of sympathetic type in conditions of perceived (A) and unperceived (B) aromatherapy and the same time frame in the control group (C).

Notations: $\mathrm{CR}=$ cardiac rate $(\mathrm{bit} / \mathrm{min}) ; \mathrm{SDNN}=$ index of total cardiac rhythm $(\mathrm{CR})$ variability; RMSSD = respiratory arrhythmia; TP $=$ total $\mathrm{CR}$ spectral power; VLP = power of very low CR frequency spectral component; LF = power of low CR frequency spectral component; $\mathrm{HF}=$ power of high $\mathrm{CR}$ frequency spectral component; $\mathrm{LF} / \mathrm{HF}=$ index of autonomic balance. ${ }^{*} p \leq .05 . * * p=.001$. 


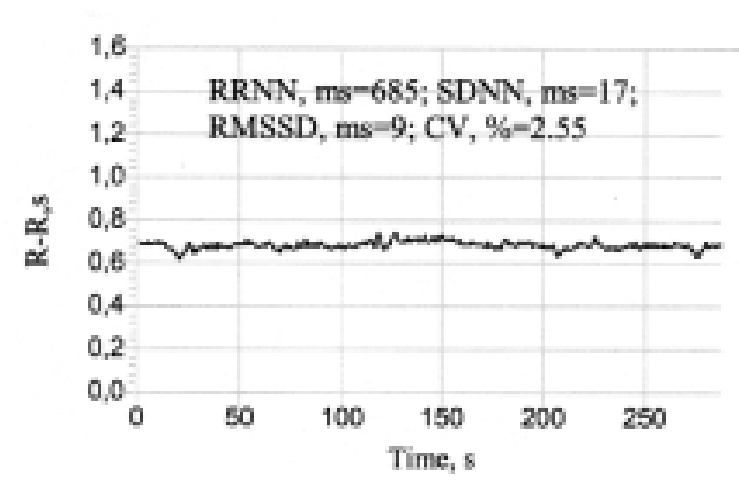

(A)

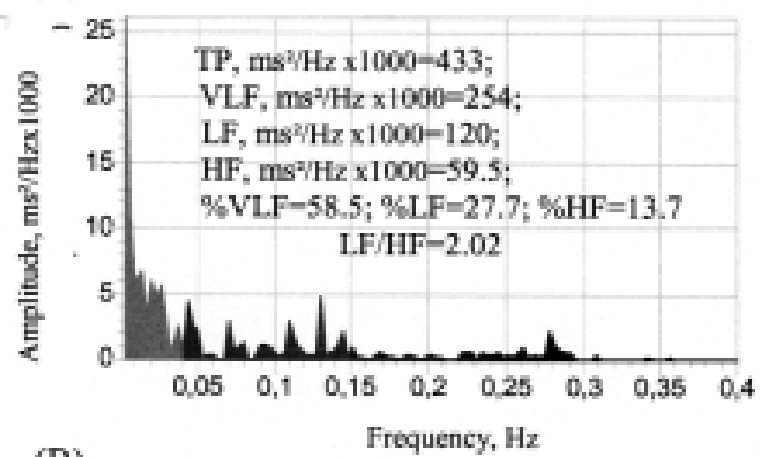

(B)
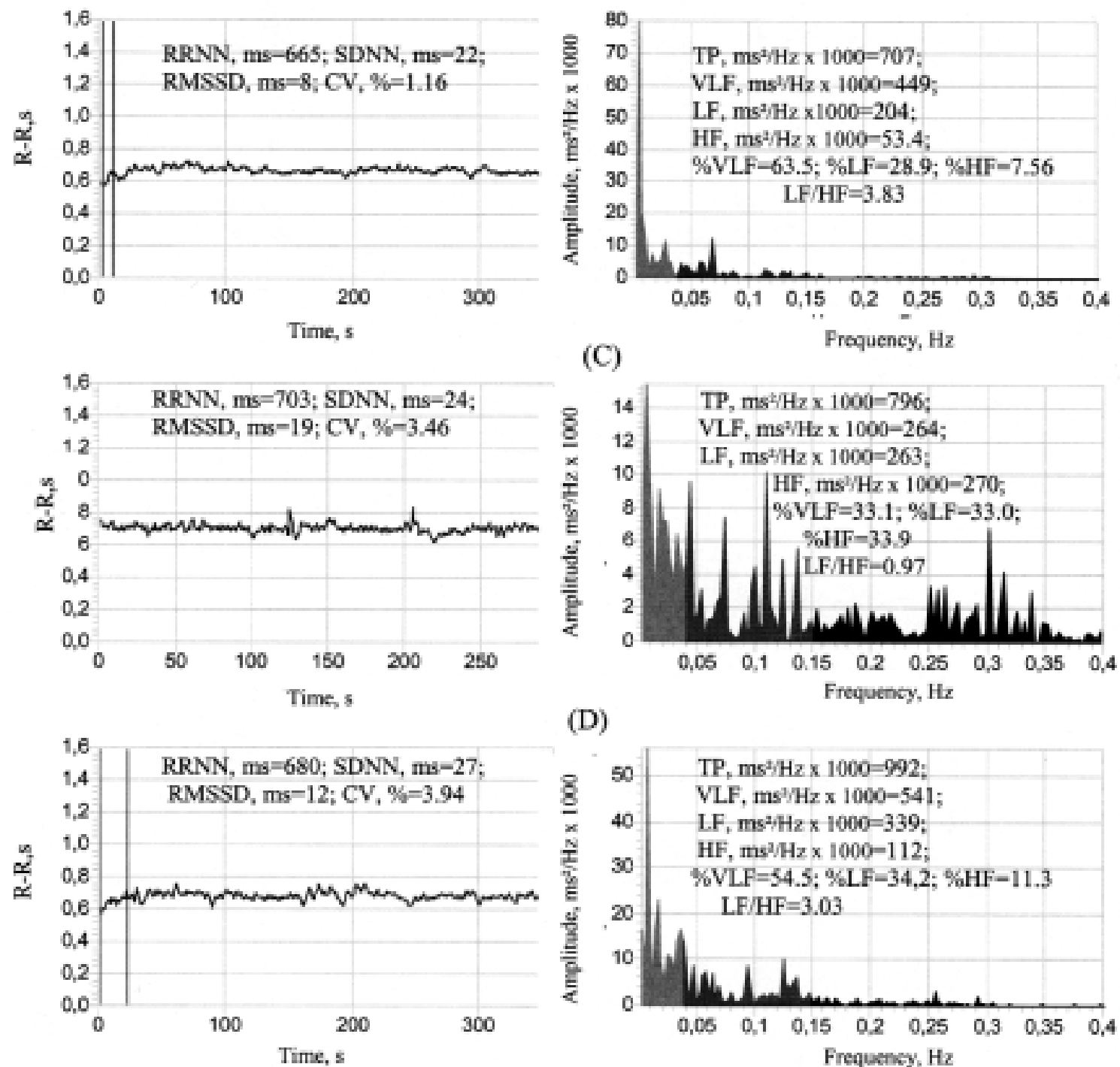

(D)

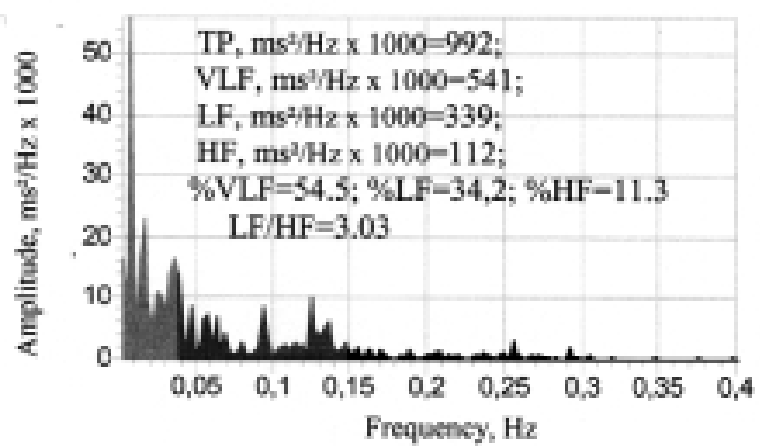

Figure 7. Indices of heart rhythm variability in a 55-year-old woman in a supine position (A) and in the active orthostatic test (B) initial state; during the after-effect of the prolonged unperceived aromatherapy: $(C)=$ supine position; $(D)=$ orthostatic test after all sensory sessions. Notations: RRNN = mean time of 300 R-R intervals of electrocardiogram; RMSSD = respiratory arrhythmia; SDNN = index of total cardiac rhythm variability $(\mathrm{CRV}) ; \mathrm{CV}=$ coefficient of the R-R intervals' time variability; $\mathrm{TP}=$ total cardiac rhythm $(\mathrm{CR})$ spectral power; $\mathrm{VLF}$ = power of very low CR frequency spectral component; $\mathrm{LF}=$ power of low CR frequency spectral component; HF = power of high $\mathrm{CR}$ frequency spectral component; $\mathrm{LF} / \mathrm{HF}=$ index of autonomic balance. 
visual information. Furthermore, if the first session resulted in an average $10 \%$ more noticeable improvement of retrieval speed in comparison to accuracy, after the $10^{\text {th }}$ session, there was greater improvement in performance accuracy compared to speed $(15 \%)$. As a result, there was practically an equally defined increase in both components of the integral index of visual productivity (by $13.7 \%$ for speed and by $15.9 \%$ for accuracy of information processing). The attained positive effects were stable and were not only maintained over time, but also increased in many women over 2 weeks after treatment. As shown in the example of the individual changes in visual productiveness, in one of the participants (Figure 8 ), the increase after the first session was notably greater than the effect after the final session. Note that similar changes were noted in the majority of participants. The extent of the effect at the end of treatment decreased, as evidence of adaptation to afferent stimulation, and not of the achievement of the upper limits of functional reserves of the brain for retrieval and processing of visual information. This is revealed by the fact that 2 weeks after treatment, visual productivity was $43.2 \%$ better than immediately after treatment, and twice as high in comparison to initial values.

Although visual stimuli were not included in the complex of sensory flow, the data presented provides evidence of the involvement of the visual system in the activation process, and furthermore, there was clear improvement of the functional state of its anterior section (increase in the accuracy of stimulus differentiation). Thus, the effect of synesthesia was a significant factor for the optimization of the functional state of various sensory systems and the CNS as a whole with monomodal and multimodal sensory flows.

Visual memory also improved, and in particular, geometric figure memory. Before the $10^{\text {th }}$ alpha-capsule session, the amount of correctly recalled figures 30 minutes after presentation was on average $66.67 \%$ higher than initially $(p=.001)$. Only in one of the participants was there a memory improvement of only $12.5 \%$; in the rest of the participants, improvement varied between 44 and $162 \%$. The final $10^{\text {th }}$ session led to further improvement in memory and a day after the completion of treatment; memory improvement comprised an average of $77.78 \%$ more than initial values. Two weeks after treatment, there was a $6.4 \%$ decrease in visual memory in comparison with the penultimate values. Thus, the possibility of the improvement of cognitive function at early stages of ageing using multimodal sensory flow has been demonstrated. It is suggested that periodic treatment with the alpha-capsule can aid the maintenance of the positive results attained. In the control group, indexes of the productivity and of visual information processing and visual nonverbal memory in half of the participants improved by $3-5 \%$ and in the remaining 3 participants, it decreased by $4-6 \%$.

As the state statokinetic stability can be assessed by the extent of integrative processes, we used its definition for the revelation of inter-central integration under the influence of comprehensive sensory flow of the alpha-capsule. It was revealed that all participants displayed a significant improvement of stability in vertical axis body deflection as a result of multisensory stimulation; at session 3-5, various participants showed an increase in certain directions of body deflections by $50-800 \%$. Figure 9 and Table 3 show that after the first session of sensory flow of the alpha-capsule, statokinetic stability in a 52-year-old woman increased most noticeably in deflections backwards and forwards; that is, in those directions in which initial stability was lowest. On the whole, maximal effect was noted after the first session. After the fifth session, and one day after it, there was an increase in stability zone, although the increase was not as pronounced as the increase following the first session, and in the demonstrated case, it remained stable especially in relation to forward deflection. In other cases, the most stable increase was not only in relation to forward, but also to backward deflection.

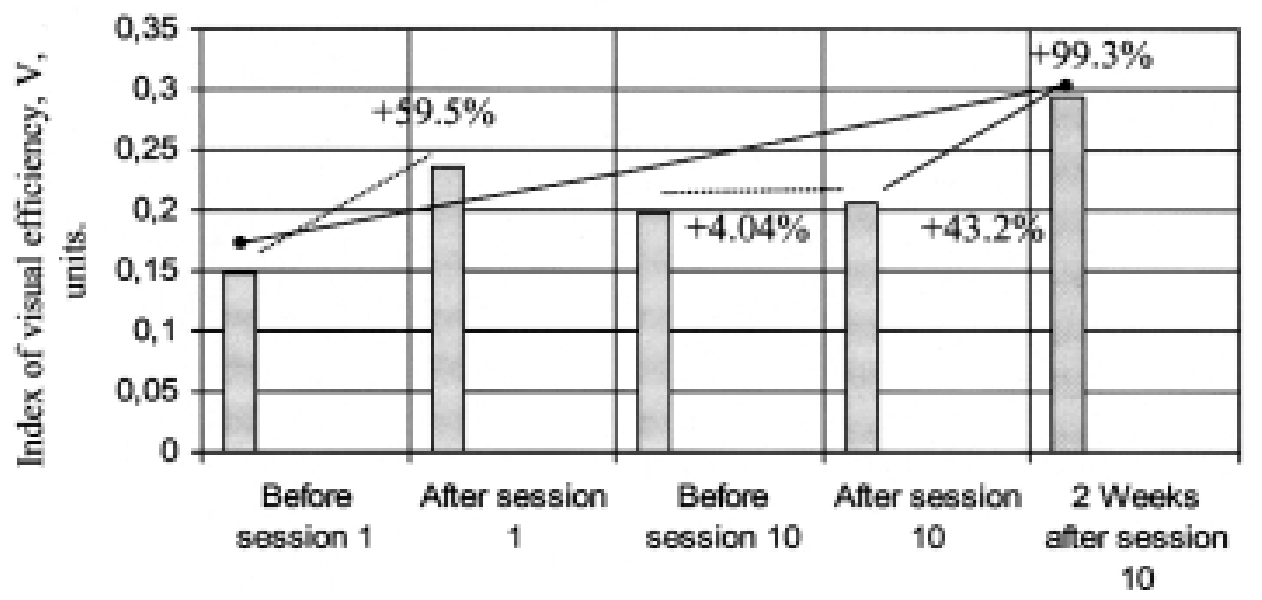

Figure 8. Individual example of the positive effect of prolonged treatment with sensory flow of the Alpha Capsule on visual efficiency (V) and stability in a 50-year-old woman. 


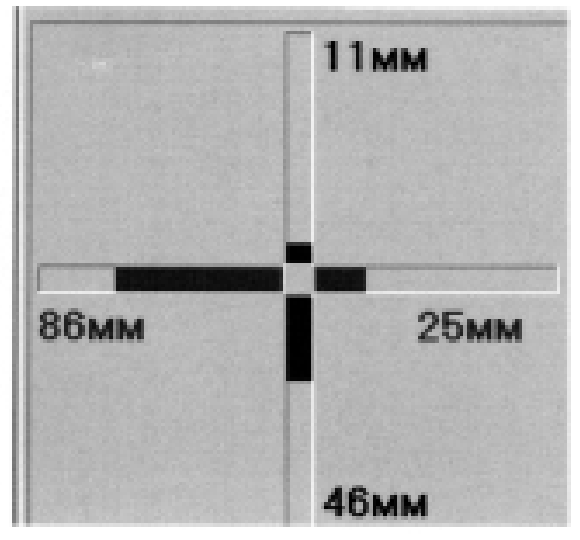

Before session one (1)

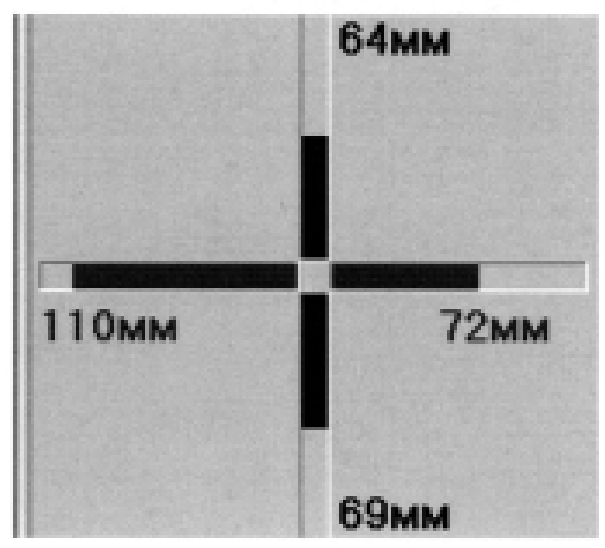

Before session five (3)

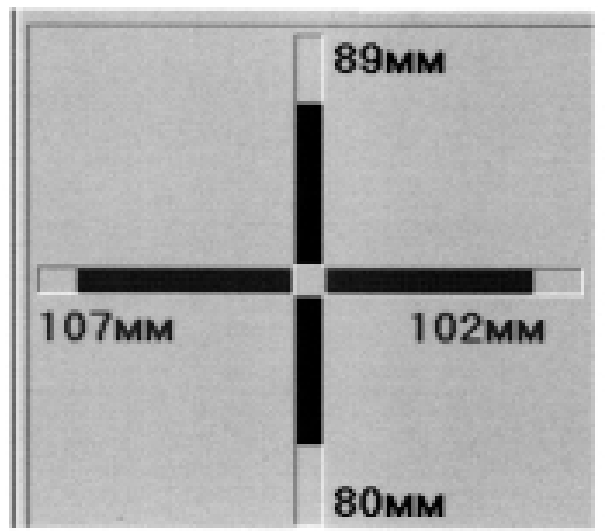

After session one (2)

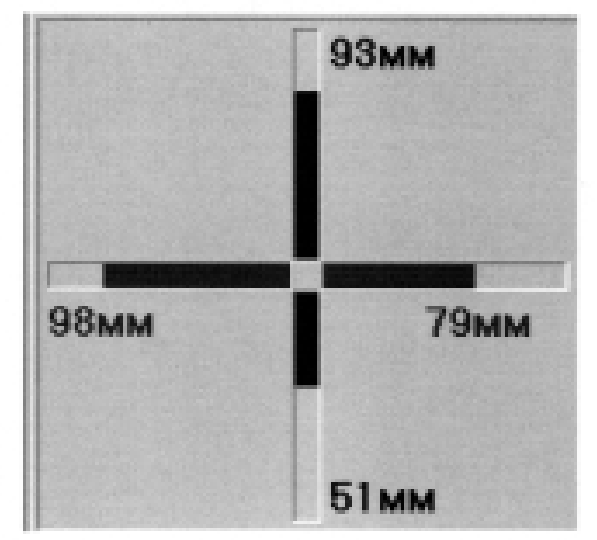

on day five after session five (4)

Figure 9. Optimization of stability zone in a 52-year-old woman with body deflection in various directions (mm) during a course of treatment with comprehensive sensory flow (Alpha Capsule).

In Table 4 are presented the data on changes of the mean indexes of the test characterizing involuntary posture control. As can be observed, under the influence of comprehensive sensory flow, according to the decrease in the area of the stabilogram and increase in the integral balance quality index, involuntary postural regulation improved significantly; most markedly with open eyes, although changes in the mean radius of pressure center deflection with open and closed eyes differed insignificantly. Note that after the first session, $23 \%$ of cases showed marked improvement of this function with closed eyes. In the control group, changes in these indexes did not exceed $\pm 5 \%$, that is, they were within the limits of natural oscillatory processes.

Table 3

Increase in Reserve Limits of Stability in a 52-Year-Old Woman in Vertical Axis Body Deflection during a Course of Treatment with Sensory Flow (Alpha Capsule) in Percentage

\begin{tabular}{lrrr}
\hline \multirow{2}{*}{ Direction of deflection } & \multicolumn{1}{c}{ Study stage } \\
\cline { 2 - 4 } & $1-2$ & $1-3$ & $1-4$ \\
\hline Forward & $+709.0 \%$ & $+481.8 \%$ & $+745.3 \%$ \\
To the right & $+264.3 \%$ & $+85.4 \%$ & $+182.14 \%$ \\
Backward & $+73.9 \%$ & $+50.0 \%$ & $+13.04 \%$ \\
To the left & $+24.4 \%$ & $+27.9 \%$ & $+13.95 \%$ \\
\hline
\end{tabular}


Table 4

Alterations in Mean Group Indexes of Functions of Vertical Stance Regulation in Women of 50-55 Years under the Influence of Five Sessions of Comprehensive Sensory Flow (Alpha Capsule) and in Controls in Percentage in Relation to Initial Values

\begin{tabular}{|c|c|c|c|}
\hline Romberg test & Stabilogram ellipse area in $\mathrm{mm}^{2}$ & Mean radius deviation OPC in $\mathrm{mm}$ & Equilibrium function quality in $\%$ \\
\hline \multirow{2}{*}{\multicolumn{4}{|c|}{$\begin{array}{c}\Delta \% \pm \mathrm{m} \\
\text { Main group }(n=20)\end{array}$}} \\
\hline & & & \\
\hline Open eyes & $-67.21 \pm 3.6$ & $-41.51 \pm 3.8$ & $+15.85 \pm 1.2$ \\
\hline Closed eyes & $-29.42 \pm 2.6^{*}$ & $-37.0 \pm 2.2$ & $+5.62 \pm 0.12 *$ \\
\hline \multicolumn{4}{|c|}{$\begin{array}{c}\Delta \% \pm \mathrm{m} \\
\text { Control group }(n=6)\end{array}$} \\
\hline Open eyes & $-3.6 \pm 1.2$ & $-2.4 \pm 0.9$ & $+1.4 \pm 1.1$ \\
\hline Closed eyes & $+2.8 \pm 1.6$ & $+2.9 \pm 1.7$ & $-2.6 \pm 1.9$ \\
\hline
\end{tabular}

Note. OPC $=$ overall pressure center.

${ }^{*} p=.05$ (Significance of variance of indices with eyes open and eyes closed.)

Changes in autonomic regulation of $\mathrm{CR}$ in women during sessions of comprehensive sensory flow of the alpha-capsule depend on the initial ratios of sympathetic and parasympathetic rhythm modulation (Figure 10). In "sympatheticotonics," indexes of autonomic balance in conditions of calm wakefulness decreased by the $10^{\text {th }}$ session in comparison to initial values by $73.5 \%$, whereas in "parasympatheticotonics," these indexes increase by $86.7 \%$. Of the sympatheticotonic participants, in $84 \%$, a 10 -session course of treatment led to a marked decrease of sympathetic reactions and an increase in parasympathetic reactions in states of calm wakefulness, as shown by the individual example of CR spectrum (Figure 11). Eighty-seven percent showed a significant increase in adequacy and economy of autonomic postural regulation. For example, one of the participants displayed a decrease in the index of autonomic balance in the orthostatic test from 10.6 to 4.2 units. In cases of initial inadequate decrease of baroreflex influence of CR in the orthostatic test, following the course of treatment with sensory activation, an adequate response with an increase in the portion of sympathetic influence was observed.

Ninety-two percents of the women with initial predominance of parasympathetic activity in CR regulation, following treatment in the alpha-capsule, also showed a balancing out of autonomic influence on CR in states of calm wakefulness, and in the orthostatic test, reactions of the sympathetic and parasympathetic nervous system became more adequate (Figure 10). Figure 12 shows the example of a participant with parasympatheticononia under the influence of comprehensive sensory flow. Treatment led to stable improvement of autonomic regulation in the orthostatic test. Prior to treatment, the $\mathrm{LF} / \mathrm{HF}$ ratio during posture

\section{口Parasympatheticotonics QSympatheticotonics}

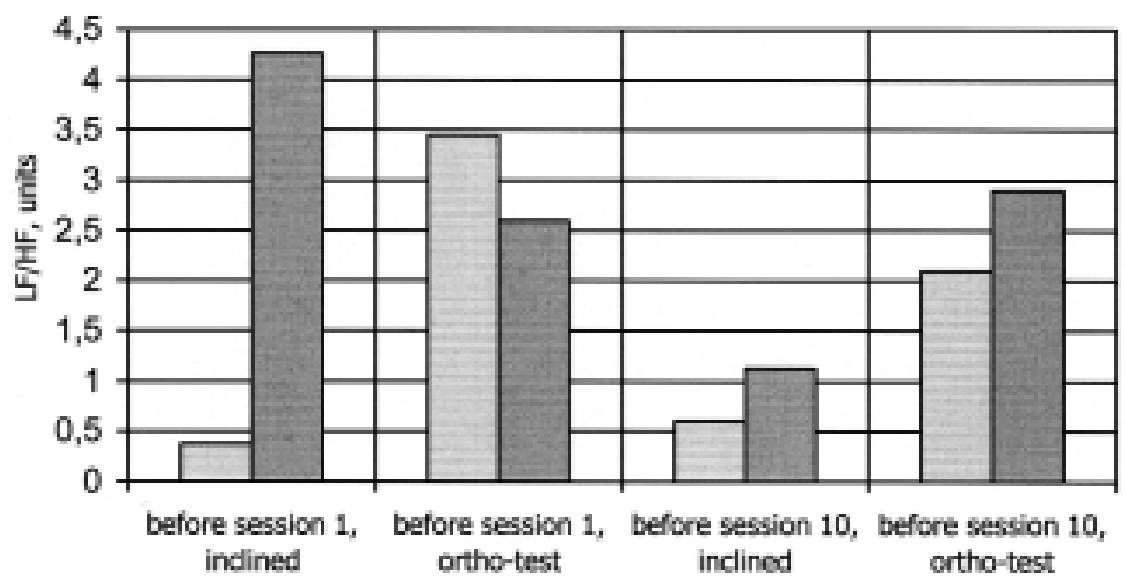

Figure 10. Alterations in mean group indexes of autonomic balance (LF/HF) in women (parasympatheticotonics and sympatheticotonics) in supine position and during the orthostatic test during the course of multimodal sensory flow (alpha capsule).

Notations: LF = power of low cardiac rhythm (CR) frequency spectral component; HF = power of high CR frequency spectral component; $\mathrm{LF} / \mathrm{HF}=$ index of autonomic balance. 
Before commencement of sensory sessions

Before the tenth session
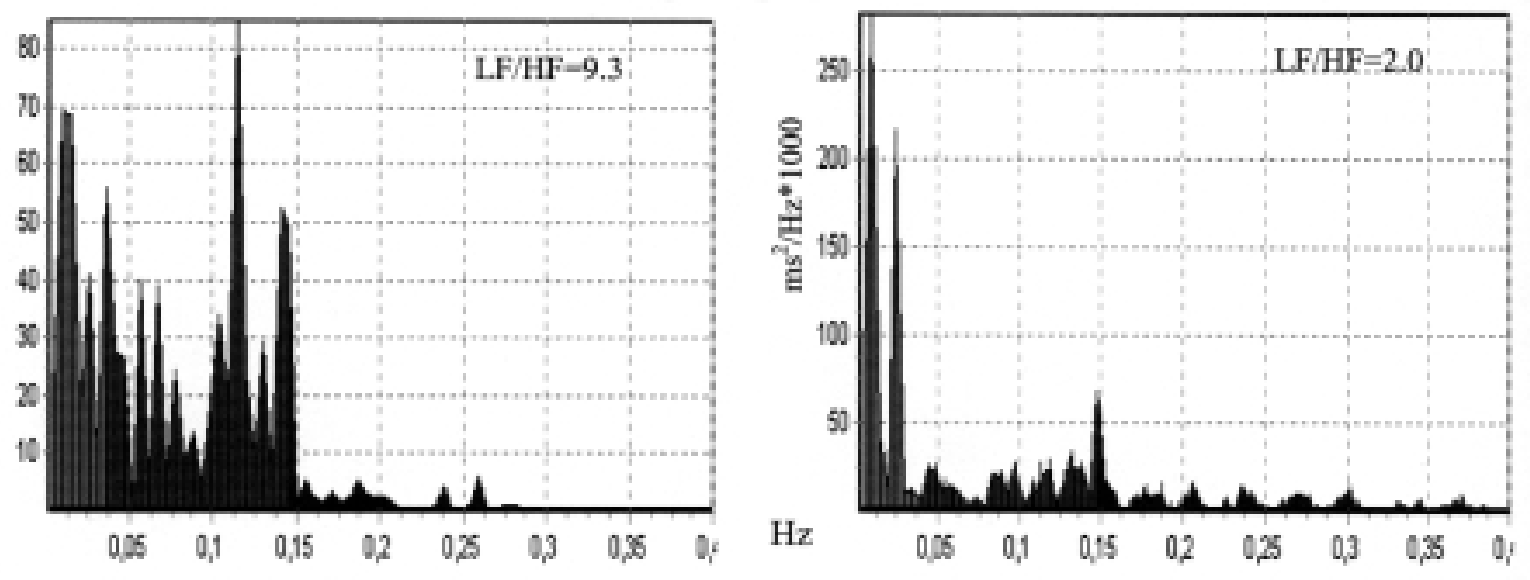

RRNN-610.0 ms; SDNN-23.0 ms;

RMSSD-12.0 ms; TP-858.9 $\mathrm{ms}^{2} / \mathrm{Hz}^{*} 1000$;

RRNN=714.0 ms; SDNN=32.0 ms;

RMSSD $-27.0 \mathrm{~ms} ; \mathrm{TP}=1177.3 \mathrm{~ms}^{2} / \mathrm{Hz}^{*} 1000$;

VLF $=280.1 \mathrm{~ms}^{2} / \mathrm{Hz} * 1000 ; \mathrm{LF}=522.5 \mathrm{~ms}^{2} / \mathrm{Hz} * 1000$

$\mathrm{HF}=56.3 \mathrm{~ms}^{2} / \mathrm{Hz}^{*} 1000$;

$\%$ VLF-32.6; \%LF- $60.8 ; \% H F=6.6$

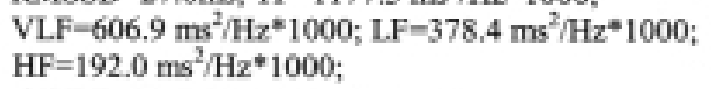

\%VLF=51.5; \%LF=32.1; \%HF=16.3

Figure 11. Decrease in sympathetic influence on cardiac rhythm variability (CRV) in conditions of calm wakefulness in a sympathicotonic woman aged 52 years at session ten of the alpha capsule.

Notations: RRNN = mean time of 300 R-R intervals of electrocardiogram; RMSSD = respiratory arrhythmia; SDNN = index of total $\mathrm{CRV}$; CV = coefficient of the R-R intervals' time variability; TP = total cardiac rhythm $(\mathrm{CR})$ spectral power; VLF = power of very low $\mathrm{CR}$ frequency spectral component; $\mathrm{LF}=$ power of low $\mathrm{CR}$ frequency spectral component; HF = power of high $\mathrm{CR}$ frequency spectral component; $\mathrm{LF} / \mathrm{HF}=$ index of autonomic balance.

change altered insignificantly by 0.2 units (from 0.4 to 0.6 ), and the activity of the parasympathetic portion of the orthostatic test remained inadequately high. After treatment with comprehensive sensory flow, and 2 weeks following completion, CR during the orthostatic test was characterized by a significant reduction of parasympathetic influence and mobilization of sympathetic reactivity. In one of the cases with initial parasympatheticotonia, the autonomic balance index did not alter at all (0.4-0.4 units), but after the 10th session of treatment, there was mobilization of sympathetic activity in the regulation of CR with orthostatic stress and the LF/HF ratio became $1.2 ; 2$ weeks after the completion of treatment, the ratio was equal to 0.8 , that is, twice as high as its values prior to treatment in the alpha-capsule.

Thus, the effect of multi-sensory flow on the regulation of CR, including its stability, is similar to that of aromatherapy. In the control group, changes in CRV were insignificant.

\section{Discussion}

One of the principal results of the present study is that conscious and unconscious sensory flows evoke an integral homeostatic response. The results obtained regarding the improvement of visual attention under the influence of the aromas of the essences used are in accordance with data that show that the essences of lavender, lemon, and mint strongly affect bioelectric brain activity (Klemm, Lutes, Hendrix, \& Warenburg, 1992). Cognitive improvement may have been caused by an increase in brain blood circulation which has been noted not only in children with a normal sense of smell, but also in children with anosmia (Nasel, Nasel, Samec, Schindler, \& Buchbauer, 1994). The reduction of high levels of anxiety that we have found, along with the improvement of participants' attention and psychophysiological resistance during the performance of tests of attention-switching in conditions of interference may be explained by the fact that essences not only activate the CNS, but also increase the concentration of GABA in inhibitory neurons of the amygdala, leading to a reduction of the effect of exogenous emotional effects (LeDoux, 1996). Furthermore, the effect of the scent of lavender exceeds that of diazepam (Tisserand, 1988).

The limbic system receives a large portion of sensory information and transfers it to centers of voluntary and involuntary movement (Buchbauer, 1993). Activation of limbic system functions is evidently associated with the noted improvement in time and accuracy of SMR under the influence of prolonged aromatherapy. Furthermore, many essences cause an acceleration of motor reactions due to the suppression of inhibitory brain systems (Boyle, 1993). Undoubtedly, the improvement in SMR is in partially due to increased attention. 
Orthostatic test

Cardiac rhythm spectrogram before the first session

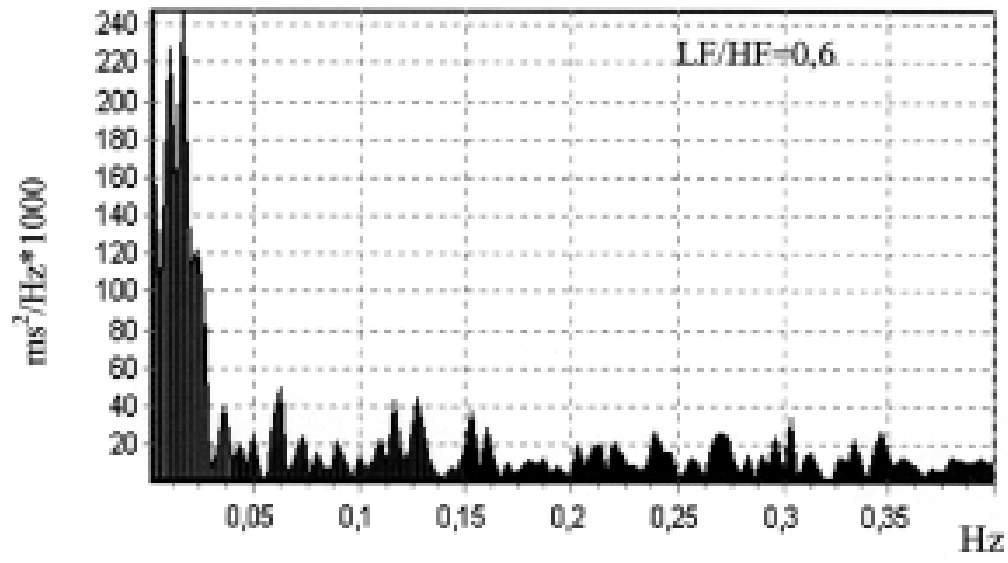

Before session ten

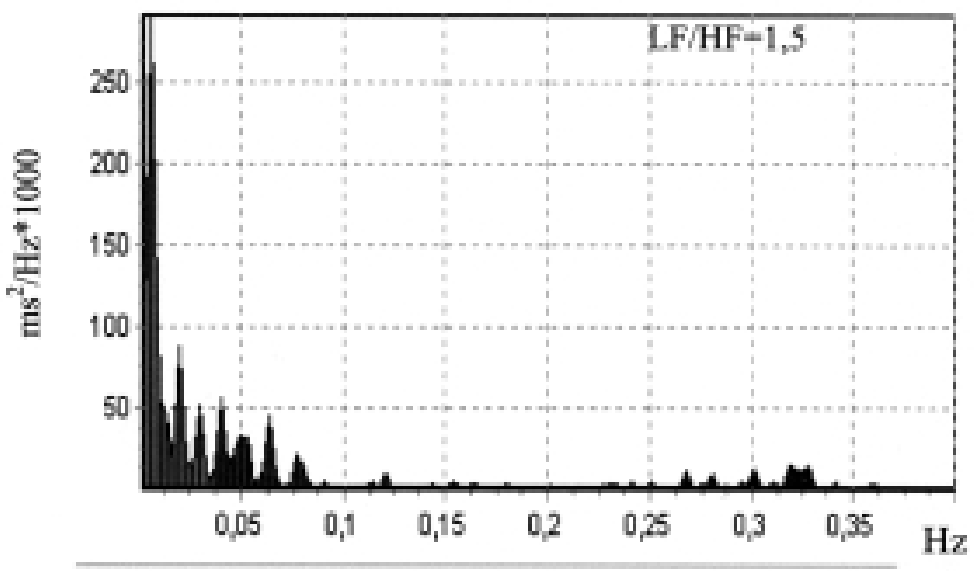

RRNN $=735.0 \mathrm{~ms} ; \mathrm{CR}=81.6$ beats $/ \mathrm{min}$; $\mathrm{SDNN}=50.0 \mathrm{~ms} ; \mathrm{RMSSD}=36.0 \mathrm{~ms}$; $\mathrm{TP}=2665.4 \mathrm{~ms}^{2} / \mathrm{Hz}^{*} 1000$; VLF $=1293.2 \mathrm{~ms}^{2} / \mathrm{Hz}^{*} 1000$; LF-498.2 $\mathrm{ms}^{2} / \mathrm{Hz}^{*} 1000$; $\mathrm{HF}=874.0 \mathrm{~ms}^{2} / \mathrm{Hz}^{*} 1000$; $\% \mathrm{VLF}=48.5 ; \% \mathrm{LF}=18.7 . \% \mathrm{HF}=32,8$.

$\mathrm{RRNN}=754.0 \mathrm{~ms} ; \mathrm{CR}=79.6$ beats $/ \mathrm{min}$; $\mathrm{SDNN}=30.0 \mathrm{~ms} ; \mathrm{RMSSD}=18.0 \mathrm{~ms}$; $\mathrm{TP}=1182.7 \mathrm{~ms}^{2} / \mathrm{Hz}^{*} 1000$; $\mathrm{VLF}=684.5 \mathrm{~ms}^{2} / \mathrm{Hz}^{*} 1000$; LF-301.2 $\mathrm{ms}^{2} / \mathrm{Hz}^{*} 1000$; $\mathrm{HF}=197.1 \mathrm{~ms}^{2} / \mathrm{Hz}^{*} 1000$; $\% \mathrm{VLF}=57.9 ; \% \mathrm{LF}=25.5 ; \% \mathrm{HF}=16.7$.

2 weeks after the completion of a course of ten sessions

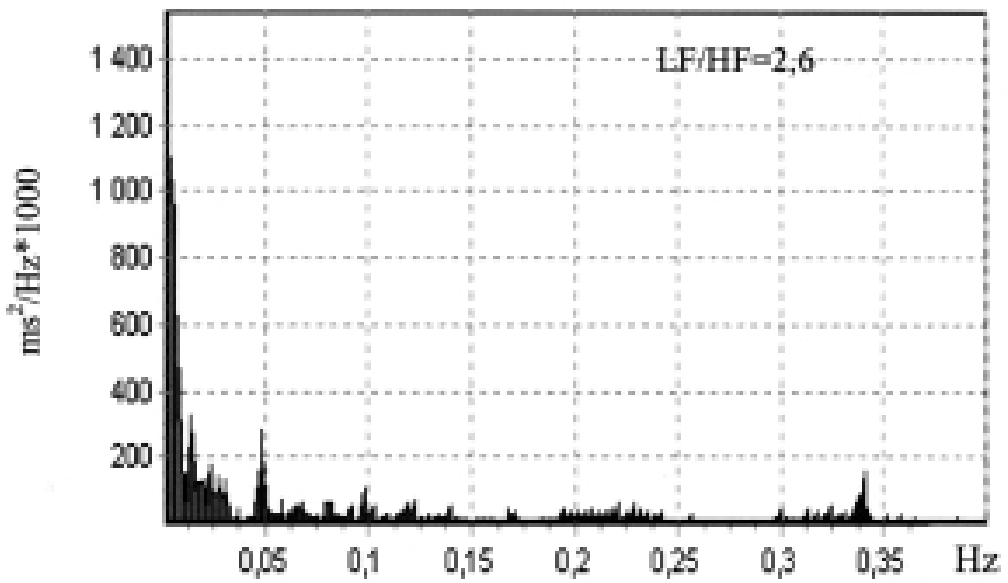

$\mathrm{RRNN}=759.0 \mathrm{~ms} ; \mathrm{CR}=79 \mathrm{beats} / \mathrm{min}$; $\mathrm{SDNN}=54.0 \mathrm{~ms} ; \mathrm{RMSSD}-26.0 \mathrm{~ms}$; $\mathrm{TP}=3693.3 \mathrm{~ms}^{2} / \mathrm{Hz}^{*} 1000$; VLF=2715.3 $\mathrm{ms}^{2} / \mathrm{Hz}^{*} 1000$; $\mathrm{LF}=709.4 \mathrm{~ms}^{2} / \mathrm{Hz}^{*} 1000$; $\mathrm{HF}=268.6 \mathrm{~ms}^{2} / \mathrm{Hz}^{*} 1000$; $\% \mathrm{VLF}=73.5 ; \% \mathrm{LF}=19.2 ; \% \mathrm{HF}=7.3$.

Figure 12. Increase in mobilization activity of the sympathetic nervous system of a woman aged 50 years with initial predominance of parasympathetic influence on cardiac rhythm $(\mathrm{LF} / \mathrm{HF}=0.4)$ during the orthostatic test at the tenth session in the alpha capsule and 2 weeks later (after-effect, $\mathrm{LF} / \mathrm{HF}=2.6$ ).

Notations: TP = total cardiac rhythm $(\mathrm{CR})$ spectral power; VLF = power of very low CR frequency spectral component; $L F=$ power of low CR frequency spectral component; $\mathrm{HF}=$ power of high $\mathrm{CR}$ frequency spectral component; LF/HF = index of autonomic balance. 
Sensory flow activates inter-sensory interrelations (Bykov $\&$ Malyarenko, 2003b). The present study provides evidence of this with the data on the processing of visual information, visio-motor reactions, and statokinetic stability. Under the influence of prolonged aromatherapy and multimodal exposure, there was significant improvement of involuntary control of vertical stance, in particular with open eyes, and of voluntary control. Evidently, these changes were aided by the improvement of attention, as in ageing, the demand for additional cognitive control of posture increases (Brown, Shumway-Cook, \& Woollacott, 1999). This fact is in accordance with two known postulates: (a) the maintenance of vertical stance in the human being is carried out using afferent information from various modality sources: visual, somatosensory, and vcestibular, although the role of olfactory flow in posture regulation has remained practically unnoticed; and (b) elimination or reduction of any of the sources of afferentation, which is common in ageing, leads to vertical postural instability (Teasdale, Stelmach, \& Breuning, 1991). The data obtained is in discord with the opinion (Melzer, Benjuva, \& Kaplanski, 2000) that age-related changes in involuntary posture regulation are irreversible. We emphasize that certain indexes of the stabilogram demonstrated the beneficial effect of unconscious aromatherapy on statokinetic stability. This was also noted in relation to positive changes in the accuracy of SMR, its time variability, and psychoemotional resistance in the attention-switching test in conditions of interference.

Due to close ties of afferent systems with the limbic system, sensory activation leads to the increase (or inhibition, in the case of certain essences) of not only of memory mechanisms, attention, and SMR but also of autonomic components of the perception of sensory information (Economides, 1986; Staubli, 1987). In the present study, as in our previous studies (Bykov \& Malyarenko, 2003a, 2003b) using the example of aromatherapy and multimodal afferent flow, we have shown the universally positive influence of sensory activation on $\mathrm{CR}$ regulation, which in particular, consists of the attainment of equilibrium between sympathetic and parasympathetic activity, and an increase in autonomic memory (stability of positive changes).

Meerson (1981) showed that repetitive influence of environmental factors is of singular importance for the formation of long-term adaptation. Such influence supports intensive functioning of neuronal brain systems, leading to the formation of new inter-neuronal systems that are typical of systemic brain structural traces, that is, memory traces. We suppose that this mechanism forms the basis for the stability of positive effects of sensory flows. Furthermore, the effects of scents and other sensory stimulation are largely due to the fact that the hippocampus is associated with the formation and activation of explicit (as proven by the present study) and emotional memory (LeDoux, 1996; Smith, Standing, \& de Man, 2002). It can be assumed that this mechanism also aids the summation of the effects of pleasant scents and multisensory influence and the achievement of the above-mentioned positive changes of various functions. At the same time, with the example of the stability of the positive changes of $\mathrm{CR}$ regulation, we revealed the activation of autonomic memory.

In addition, training the olfactory and other sensory systems aids the increase of the sensitivity of the respective functional system and the stabilization of extending the limits of adaptation and brain activation, especially in associative zones (Bykov \& Malyarenko, 2003b).

Uryvaev, Golubeva, and Netchaev (1986) showed that the short-term influence of the unconscious scents sometimes leads to greater activation of inter-system interrelations than the effects of conscious scents. As is well known, weak effects on the ageing organism are physiological in nature, an expedient in terms of the economy of energy reverses that opposes ageing. Specifically, these effects cause adaptation reactions and lead to a state of higher reactivity, similar to that of young participants, that is, weak adequate effects. Minimal triggering information can practically activate the participant's entire information thesaurus, that is, information memory (Kuraev \& Tchorajan, 2001). It has been shown that physiological and psychological effects are evoked in response to unconscious scents (Cupchik, Phillips, \& Truong, 2005; Hays, 2003; Jacob, Kinnunen, Metz, Cooper, \& McClintock, 2001; Levin, 2004; Milotic, 2003). In the present study with prolonged aromatherapy with an unconscious scent source, $\mathrm{CR}$ reactions, although differing insignificantly from the effects of conscious olfactory sensory flow, in some cases, exceeded these latter effects. We have also revealed the role of unconscious aromatherapy in the improvement of statokinetic regulation, SMR, and attention and therefore not only confirmed the available facts about the role of unconscious sensory flows, but also added to them.

In conclusion, aromatherapy and multimodal sensory activation are highly effective methods that aid the recuperation of the organism. Primarily, this is achieved by the utilization of physical and emotional characteristics of sensory flows; of importance is the fact that they affect practically the entire brain and memory system, with consolidation of the attained effects. The duration of the after-effects of essences is also determined by the chemical nature of olfactory activation and the fact that their molecules enter the organism through various channels and affect several regulation levels of physiological systems, influencing their interrelationship, increasing the brain's energetic potential, and facilitating the formation of a systemic response (Buckle, 2004; Price \& Price, 2002). To a greater extent, an increase in brain energy can be attained using equipment for comprehensive sensory flow, in which activation of several sensory systems occurs, including the olfactory system. The efficacy of the comprehensive use of physical factors is based on multilevel effects on the CNS, activation of integrative processes, and an increase in the duration of after-effects (Malyarenko, Bykov, \& Malyarenko, 
2005). Nevertheless, one should bear in mind that excessive increase of activated of sensory systems does not necessarily lead to the optimization of the human functional state.

Thus, we have shown that sensory systems, being the "window to the brain," allow-with the aid of conscious and unconscious sensory flows - the reformation of various functions and offer remarkable promise for their widespread use in the correction of changes at early stages of the ageing process. The results obtained about the role of conscious and unconscious aromatherapy in the improvement of psycho-emotional states and statokinetic stability, as well as optimization of visual information processing, SMR, attention, memory, and CR regulation are of interest not only to specialists in the fields of psycho-correction, psychophysiology, gerontology, neurology, and rehabilitation medicine but also in the fields of labor and sports psychophysiology.

\section{References}

Allum, J.H., \& Shepard, N.T. (1999). An overreview of the clinical use of dynamic posturography in differential diagnosis of balance disorders. Journal Vestibular Research, 9, 223.

Alpha $2010^{\mathrm{TM}}$ Spa System (2002). Owner's service manual. Minneapolis, MN.

Appenzeller, O. (1992). Aging and the autonomic nervous system. Neurology and Neurosurgery, 5. 464-467.

Baltes, P.B., \& Lindenberger, U. (1997). Emergence of a powerful connection between sensory and cognitive functions across the adult life span: A new window to the study of cognitive aging? Psychology and Aging, 12, 12-21.

Bannister, R.F., \& Mathias, C. (Eds.). (1992). Autonomic failure. Oxford: Oxford University Press.

Bashore, T.R., Ridderinkhof, K.R., \& van der Molen, M.W. (1997). The decline of cognitive processing speed in old age. Current Directions in Psychological Science, 6, 163-169.

Boyle, R.J. (1993). Human reliability, risk assessment and control. Version 2. Occupational Health and Safety Training Unit. Portsmouth University Enterprises Ltd, Section 9-13.

Brown, L., Shumway-Cook, A., \& Woollacott, M. (1999). Attentional demands and postural recovery: The effects of aging. Journal of Gerontology, 54, 165-171.

Buchbauer, G.(1993). Biological effects of fragrances and essential oils. Perfumer and Flavorist, 18, 19-24.

Buckle, J. (2004). Clinical aromatherapy. (2 ${ }^{\text {nd }}$ ed). London: Elsevier.

Bykov, A.T., \& Malyarenko, T.N. (2003a). Aromaterapia v upravlenii vegetativnoi regulatciei ritma cerdtca [Aromatherapy in the control over autonomic regulation of heart rhythm] Voprosy Kurortologii, Fizioterapii, and Lechebnoi Fizicheskoi Kulturi, 6, 6-9.

Bykov, A.T., \& Malyarenko, T.N. (2003b). Sensornyj pritok $i$ optimizatsia funktcij cerdtca i mozga [Sensory inflows and heart and brain function optimization]. Rostov-on-Don: PiligrimPark.
Cooke, B., \& Ernst, E. (2000). Aromatherapy: A systematic review. British Journal General Practice, 50, 493-496.

Cupchik, G.C., Phillips, K., \& Truong, H. (2005). Sensitivity to the cognitive and affective qualities of odors. Cognition and Emotion, 19, 121-131.

Dawes, P.J.D., Dawes, M.T., \& Williams, S.M. (2004). The smell map: Commonality of odour perception confirmed. Clinical Otolaryngology, 29, 648-654.

Doty, R.L. (2001). Olfaction. Annual Review of Psychology, 52, 423-452.

Economides, S. (1986). Integration centrale de l'information olfactive chez l'homme. Bulleteen SFECA, 1, 178-185.

Fokin, V.F., \& Ponomareva, N.V. (2003). Energetitceskaja fiziologija mozga [Neuroenergetics and brain physiology]. Moscow: ANIDOR.

Franchomme, P., \& Pénoël, D. (1990). L'aromathérapipie exactement. Limoges, France: Jollois.

Galan, R.F., Sachse, S., Galizia, C.G., \& Herz, A.V.M. (2004). Odor-driven attractor dynamics in the antennal lobe allow the simple and rapid olfactory pattern classification. Neural Computation, 16, 999-1012.

Gordeeva, O.V. (2004a). Izmenennye sostojania coznania pri sensornoj deprivatsii (Soobtshenie 1) [Changed states of consciousness under sensory deprivation]. Vesntik Moskovskogo Universiteta, 1, 70-87.

Gordeeva, O.V. (2004b). Izmenennye sostojania coznania pri sensornoj deprivatsii (Soobshenie 1) [Changed states of consciousness under sensory deprivation]. Vesntik Moskovskogo Gosudarstvennogo Universiteta, 2, 66-83.

Graves, A.B., Bowen, J.D., Rajaram, L., McCormick, W.C., \& McCurry, S.M. (1999). Impaired olfaction as a marker for cognitive decline: Interaction with apoliprotein E epsilon4 status. Neurology, 53, 1480-1487.

Hawkes, C.H., Shepard, B.C., \& Daniel, S.E. (1997). Olfactory dysfunction in Parkinson's disease. Journal of Neurology, Neurosurgery, \& Psychiatry, 62, 436-446.

Hays, W. (2003). Human pheromones: Have they been demonstrated? Behavioral and Ecological Sociobiology, 54, 89-97.

Herz, R.S., Beland, S.L., \& Hellerstein, M. (2004). Changing odor hedonic perception through emotional associations in humans. International Journal of Comparative Psychology, 17, 315338.

Herz, R.S., Schankler, C., \& Beland, S. (2004). Olfaction, emotion and associative learning. Motivation and Emotion, 28, 363383.

Jacob, S., Kinnunen, L.H., Metz, J., Cooper, M., \& McClintock, M.K. (2001). Sustained human chemosignal unconsciously alters brain function. Neuroreport, 12, 2391-2394.

Khavinson, V.Kh., Kvetnoy, I.M., Ingel, I.E., \& Marianovich, A.T. (2003). Vozrastnaya involutsia organov i tkanej [Age-related involution of organs and tissues]. Uspekhi Physiologicheskich Nauk, 34, 78-91.

King, J. (1994). Scientific status of aromatherapy. Perspectives Biological Medicine, 37, 409-415. 
Klemm, W.R., Lutes, S.D., Hendrix, D.W., \& Warenburg, S. (1992). Topographical EEG maps of human response to odors. Chemical Sciences, 17, 347-361.

Kuraev, G.A., \& Tchorajan, O.G. (2001). Nekotorye kiberneticheskie aspecty sostoyania zdorovja [Some cybernetic aspects of the health status]. Valeologia, 3, 4-7.

LeDoux, J. (1996). The emotional brain. New York: Simon \& Schuster.

Levin, R.J. (2004). Smells and taste: Their putative influence on sexual activity in humans. Sexual and Relationship Therapy, 19, 451-462.

Loseva, E.V., \& Karnup, C.V. (2004). Neirogenes v zreloi obonyatelnoj lukovitse i ego vozmozhnoe funrtsionalnoe prednaznatchenie [Neurogenesis in the nature olfactory bulb and its possible functional destination]. Uspechi Fiziologitcheskich Nauk, 35, 11-18.

Malcolm, A.D.B. (2004). Not to be sniffed at: The Nobel Prize in Physiology and Medicine 2004. Journal of Biological Education, 39, 11.

Malliani, A. (1996). Heart rate variability: A challenge for a new way of thinking. Journal Cardiac Failure, 2, 197-202.

Malyarenko,Yu.E., Bykov, A.T., \& Malyarenko, T.N. (2005). Ot metodologii sistemnogo podhoda $\mathrm{k}$ tehnologii kompleksnoi korrektsii funktcionalnogo sostojania [From methodology of the system approach to technology of the complex correction of functional status]. Valeologia, 3, 9-16.

Malyarenko,Yu.E., Bykov, A.T., Malyarenko, T.N., Matyukhov, A.V., \& Korabelnikova, E.A. (2005). Izmenenia serdechnososudistoi sistemy $i$ ee vegetativnoi regulatcii pri fisiologitceskom starenii kak determinanta formirovania pogranichnogo sostoyania organisma [Changes of cardiovascular system and its autonomic control during physiological ageing as the determinant of forming the borderline state of an organism]. Clinical Physiology of Circulation, 1, 59-70.

Manchester, D., Voollacott, M.N., Zederbauer-Hylton, N., \& Marino, O. (1989). Visual, vestibular and somatosensory control in the older adult. Journal Gerontology, 4, 118-126.

Meerson, F.Z. (1981). Adaptatsia, stress, profilaktka [Adaptation, stress, and prevention]. Moscow: Meditcina.

Melzer, I., Benjuva, N., \& Kaplanski, J. (2000). Age-related changes in muscle strength and fatigue. Isokinetics and Exercise Science, 8,73 .
Milotic, D. (2003). The impact of fragrance on consumer choice. Journal of Consumer Behavior, 3, 179-191.

Nasel, B., Nasel, Ch., Samec, P., Schindler, E., \& Buchbauer, G. (1994). Functional imaging of effects of fragrances on the human brain after prolonged inhalation. Chemical Sciences, 19, 359-364.

Price, Sh., \& Price, L. (2002). Aromatherapy for health professionals ( $2^{\text {nd }}$ ed). Edinburgh, UK: Churchill Livingston.

Roebuck, A. (1995). Aroma-SPA therapy. Toronto: Anessence.

Roulier, G. (1990). Les huiles essentielles pour votre sante. StJean-de-Braye, France: Dangles.

Royet, J.-P., Koenig, O., Gregoire, M-C., Cinotti, L., \& Lavene, F. (2000). Functional anatomy of perceptual and semantic processing of odors. Journal of Cognitive Neurosciences, 11, 94-109.

Smith, D.G., Standing, L., \& de Man, A. (2002).Verbal memory elicited by ambient odor. Perceptual and Motor Skills, 74, 339-343.

Staubli, U. (1987). Olfaction and the «Data» memory system. Behavioral Neurosciences, 101, 757- 766.

Stuart-Hamilton, I. (2000). The psychology of ageing. ( $\left.3^{\text {rd }} \mathrm{ed}\right)$. London/Philadelphia: Jessica Kingsley.

Sudakov, K.V. (Ed.). (1987). Funktsionalnye systemy organisma [Functional systems of the organism]. Moscow: Meditsina.

Task Force of the European Society of Cardiology and North American Society of Pacing and Electrophysiology (1996). Heart rate variability. Standards of measurement, physiological interpretation and clinical use. Circulation, 93, 1043-1065.

Teasdale, N., Stelmach, G.E., \& Breuning, A. (1991). Postural sway characteristics of the elderly under normal and altered visual and support surface conditions. Journal of Gerontology, 46, 238-243.

Tisserand, R. (1988). Lavender beats benzodiazepines. International Journal of Aromatherapy, 1, 1-2.

Uryvaev, Yu.V., Golubeva, N.K., \& Nechaev, A.M. (1986). O razlichii vegetativnyh reaktsij cheloveka na osoznavaemye $\mathrm{i}$ neocoznavaemye zapahi [About the difference of the human's autonomic reactions to conscious and unconscious smells]. Doklady Akademii Nauk SSSR, 290, 501-504.

Received April 7, 2006

Review received May 27, 2006 Accepted July 31, 2006 